\title{
Development of Gold-PAGE: towards the electrophoretic analysis of sulphurous biopolymers
}

Emerald R. Taylor, ${ }^{a}$ Silvia Cavuoto, ${ }^{a}$ David M. Beal, ${ }^{b}$ Sophie Caujolle, ${ }^{a}$ Adrian Podoleanu, ${ }^{a}$ and Christopher J. Serpella*

\footnotetext{
a School of Physical Sciences, Ingram Building, University of Kent, Canterbury, Kent, CT2 7NH, UK

${ }^{b}$ School of Biosciences, Stacey Building, University of Kent, Canterbury, Kent, CT2 7NJ, UK Email: C.J.Serpell@kent.ac.uk / Twitter: @CJSerpell
}

\section{Supplementary Information}

\section{Contents}

Materials, instrumentation, and general considerations

Synthesis and characterisation of AuNPs 4

Gel casting and running methodology 15

$\begin{array}{ll}\text { Rheology } & 17\end{array}$

Optical coherence tomography 25

Transmission electron microscopy of gel matrices 27

$\begin{array}{ll}\text { References } & 30\end{array}$ 


\section{Materials, instrumentation, and general considerations}

Hydrogen tetrachloroaurate; Aliquat ${ }^{\circledR} 336$ and sodium borohydride, urea, EDTA and isopropanol were purchased from Acros. 4-dimethylamino pyridine was purchased from Fluorochem. Toluene, boric acid and acrylamide/bisacrylamide 37.5:1 solution was purchased from Fisher Scientific. Ammonium phosphate, $\mathrm{N}, \mathrm{N}, \mathrm{N}^{\prime}, \mathrm{N}$ '-tetramethylethylenediamine (TEMED), cetyltrimethylammonium bromide (CTAB), and Tris; glycine, glycerol, bromophenol blue, expedeon instant blue and Ellman's reagent were purchased from Sigma Aldrich. Stains-all was purchased from Alfa-Aesar.

DNA strands were purchased from Integrated DNA Technologies. The strand sequences were as follows (phosphorothioate linkages are designated with *):

0S: AAGCTTTTTTGACTGACTGCAGCGATTCTTGATCGCCACGGTCTGGAAAAAGAG

1S-term: A*AGCTTTTTTGACTGACTGCAGCGATTCTTGATCGCCACGGTCTGGAAAAAGAG.

1S-cent: AAGCTTTTTTGACTGACTGCAG*CGATTCTTGATCGCCACGGTCTGGAAAAAGAG.

2S: A*AGCTTTTTTGACTGACTGCAG*CGATTCTTGATCGCCACGGTCTGGAAAAAGAG.

3S: A*AGCTTTTTTGACTGACTGCAG*CGATTCTTGATCGCCACGGTCTGG*AAAAAGAG.

SH: 5ThiolMC6D-AAGCTTTITTGACTGACTGCAGCGATTCTTGATCGCCACGGTCTGGAAAAAGAG.

0S-Trn: AAG CTT TTT TGA CTG ACT GCA GCG ATT

1S-Trn: A*AG CTT TTT TGA CTG ACT GCA GCG ATT

2S-Trn: A*AG CTT TTT TGA C*TG ACT GCA GCG ATT

3S-Trn: A*AG CTT TTT TGA C*TG ACT GCA GC*G ATT

OS-Pri: TGA CTG TGA ACG TTC GAG ATG A

3S-Pri: $T *$ GA CTG TGA AC*G TTC GAG AT*G A

Protein samples were purchased from Sigma Aldrich and reduced using Ellman's reagent. The proteins used were as follows:

Lys: Lysozyme from hen's egg white, containing 147 amino acids and 12 sulphurs.

BSA: Bovine Serum Albumin, containing 607 amino acids and 40 sulphurs.

RNAse: RNAse A, containing 150 amino acids and 13 sulphurs.

GST: Glutathione-S-Transferase, containing 209 amino acids and 6 sulphurs.

TAMg buffer is composed of $45 \mathrm{mM}$ Tris and $12.5 \mathrm{mM} \mathrm{Mg}(\mathrm{OAc})_{2} \cdot 6 \mathrm{H}_{2} \mathrm{O}$ with pH adjusted to 8.0 using glacial acetic acid. TBE buffer is $90 \mathrm{mM}$ Tris, $90 \mathrm{mM}$ boric acid and $1.1 \mathrm{mM}$ EDTA with a pH of 8.0. Denaturing PAGE is conducted in the presence of $2.4 \mathrm{M}$ urea. Tris- $\mathrm{HCl}$ buffer is composed of Tris base dissolved in water and $\mathrm{pH}$ adjusted to 6.8 with hydrochloric acid to a concentration of $0.375 \mathrm{M}$ and $1.5 \mathrm{M}$. Tris glycine buffer (running buffer) is composed of $25 \mathrm{mM}$ Tris and $192 \mathrm{mM}$ glycine.

Protein samples were reduced as follows:

Protein was dissolved in $6 \mathrm{M}$ guanidine in $20 \mathrm{mM}$ tris, the $\mathrm{pH}$ was adjusted to $\mathrm{pH} 8$ with $0.5 \mathrm{M} \mathrm{NaOH}$. The absorbance at $\mathrm{A} 280$ was taken and used in conjunction with the mass coefficient to calculate protein concentration in $\mathrm{mg} \mathrm{mL}^{-1} .1 \mathrm{M}$ DTT was added to a final concentration of $33 \mathrm{mM}$ DTT. The column was rolled overnight before being purified by PD10 column using $0.1 \mathrm{M}$ acetic acid. $1 \mathrm{M}$ tris solution was combined with Ellman's reagent and water, the absorbance was measured at A280 with an absorbance of zero. Protein solution was added to the Ellman's reagent solution and retested. An absorbance of $0.542 \mathrm{AU}$ and a visible colour change from colourless to yellow confirmed the presence of reduced thiols.

Dynamic light scattering (DLS) analysis was carried out on a Malvern Zeitasizer Nano ZS. The sample was equilibrated to $25^{\circ} \mathrm{C}$ before 14 consecutive scans of the sample were taken.

UV-visible spectroscopy data was collected on a Shimadzu UV-1800 spectrometer. The parameters of the scan were set to scan between $400-600 \mathrm{~nm} .2 \mathrm{~mL}$ of the diluted AuNP sample was deposited into a clean 
cuvette and placed into the spectrometer. The sample was scanned and a graph with a single peak was produced. The data values were collected and used to calculate the AuNP diameter using the literature. ${ }^{1} \mathrm{~A}$ ratio between the peak value and the value at $450 \mathrm{~nm}$ was used to give the diameter of the AuNPs.

Transmission electron microscopy (TEM) was performed on a Jeol 1230, operating at an accelerating voltage of $80 \mathrm{kV}$ and the images were recorded with a Gatan Multiscan 790 digital camera. Solutions of AuNPs were drop cast onto carbon-coated copper grids. The grids were left to dry under the direct heat of a lamp. Images were taken by lan Brown (University of Kent, School of Biosciences). Images were analysed using Fiji Image J software ${ }^{2}$. The analysis parameters were; size $\mathrm{nm}^{2}$ (5-100), and circularity (0.50-1.00). The data collected was used to back-calculate the diameter of each particles from its area.

Rheometry was conducted using an Anton Paar MCR302 Modular Compact Rheometer running RheoCompass software 1.17.544. The measuring system (vain) was a D-CP/PP7 (Anton Paar) and the measuring plate was a D-PP25/ P2 with a diameter of $25 \mathrm{~mm}$, and serrated teeth $(0.05 \mathrm{~mm})$. 


\section{Synthesis and characterisation of AuNPs}

\section{Citrate AuNPs}

$25 \mathrm{mg}$ of hydrogen tetrachloroaurate $\left(\mathrm{HAuCl}_{4}\right)$ was dissolved in $50 \mathrm{~mL}$ of deionized water and the solution was brought to a boil with stirring under reflux. A trisodium citrate solution ( $25 \mathrm{mg}$ in $1 \mathrm{~mL}$ milliQ water) was then added, the reaction mixture was kept boiling for 5 minutes after observed colour change to red. The gold suspension was then cooled. ${ }^{3}$ The citrate-protected nanoparticles were stored at $4{ }^{\circ} \mathrm{C}$ for up to two months. The approximate concentration of citrate AuNPs was $0.05 \mathrm{mg} \mathrm{Au} \mathrm{mL}^{-1}$.

Twenty-two TEM images of citrate AuNPs were captured (Fig. S2). The citrate particles have a standard deviation of $3.83 \mathrm{~nm}$ and a mean of $17.76 \mathrm{~nm}$ (Fig. S1). The majority of particles examined exhibit a slightly elongated spherical morphology.

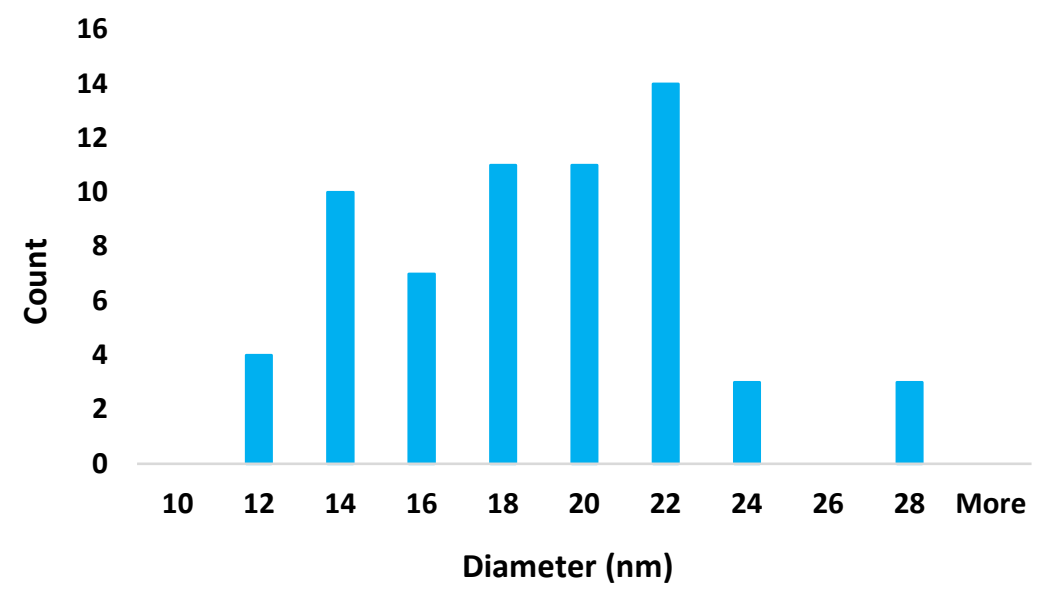

Figure S1. Histogram showing the distribution of citrate capped AuNPs ( $n=64)$.

DNA binding was analysed by UV-Vis (Fig. S3). Four solutions were prepared by diluting $1 \mathrm{~mL}$ of citrate AuNPs in $10 \mathrm{~mL}$ deionised water $\left(0.01 \mathrm{mg} \mathrm{Au} \mathrm{mL}^{-1}\right) .2 \mathrm{~mL}$ of this solution was added to four vials, to three of the vials $5 \mu \mathrm{L}$ of $100 \mu \mathrm{M}$ DNA in deionised water; $\mathbf{0 S}, \mathbf{3 S}$ and $\mathbf{S H}$ were added respectively. 


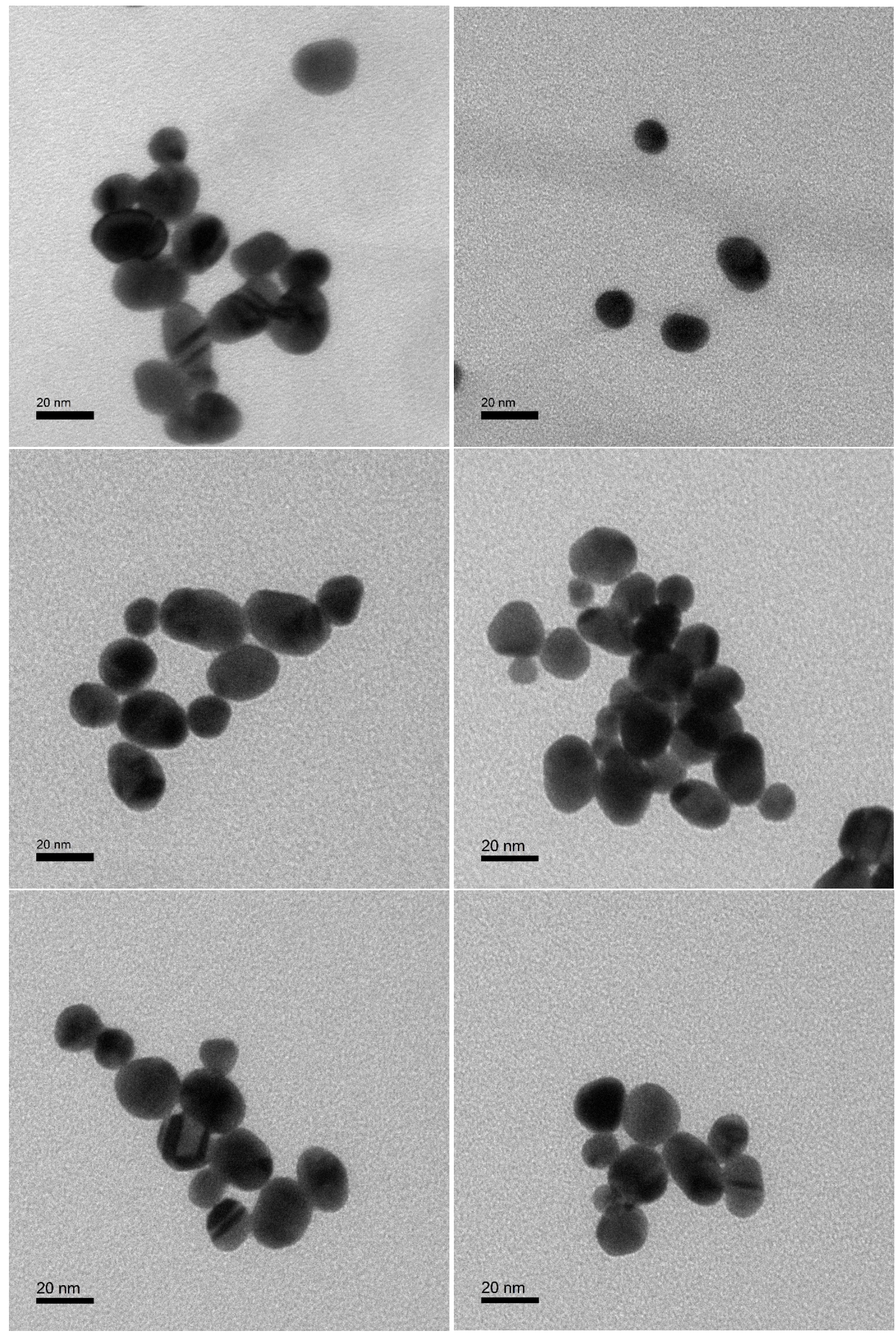

Figure S2. TEM images of citrate AuNPs. 
DLS analysis was carried out on citrate AuNPs and DNA binding affinity, but the data were of low quality.
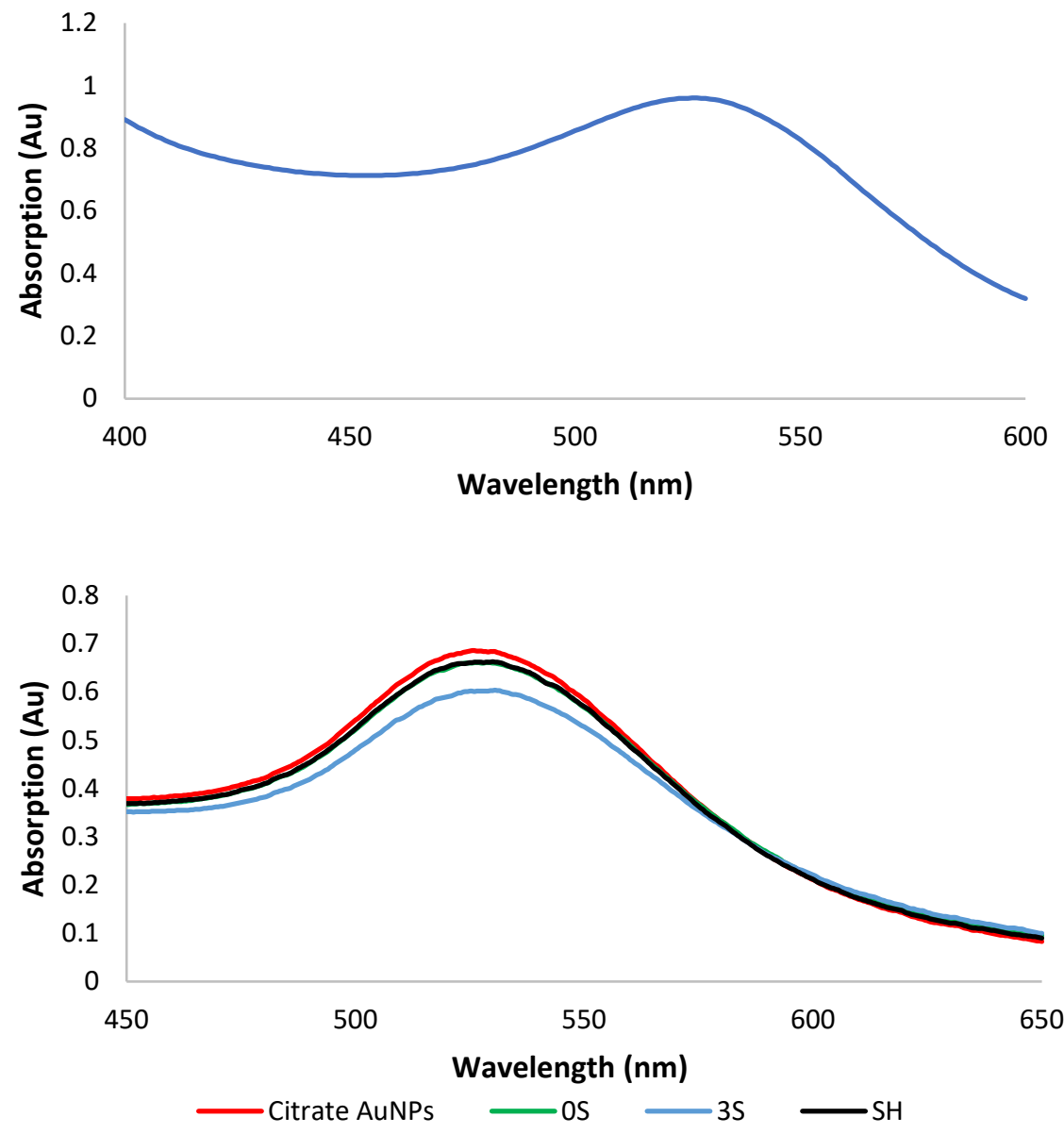

Figure S3. UV-visible spectrum of citrate AuNPs (top). Calculated diameter $=10 \mathrm{~nm}$. UV-visible spectrum of citrate AuNPs - DNA binding affinity (bottom). 


\section{CTAB AuNPs}

CTAB AuNPs were synthesised by using an adapted version of the Brust method. A solution of hydrogen tetrachloroaurate $\left(\mathrm{HAuCl}_{4}\right)$ was prepared in deionised water $(200 \mathrm{mg}$ in $16 \mathrm{~mL}$ ). This solution was placed into a round bottom flask containing a magnetic stir bar. To this a solution of CTAB in deionised water (1.224 $\mathrm{g}$ in $40 \mathrm{~mL}$ ) was added and the solution left to stir for one hour. A solution of sodium borohydride in deionised water $(210 \mathrm{mg}$ in $12 \mathrm{~mL}$ ) was added drop-wise to the stirring solution. A colour change from orange, to brown, to dark red occurred and the solution left to stir for a minimum of twenty hours. The resulting solution was dark purple. The CTAB-protected nanoparticles were collected into $50 \mathrm{~mL}$ falcon tubes, labelled and stored at $4{ }^{\circ} \mathrm{C}$ for at least six weeks. The approximate concentration of CTAB AuNPs was $3.33 \mathrm{mg} \mathrm{Au} \mathrm{mL}^{-1}$.

Eleven TEM images were captured of CTAB AuNPs (Fig. S8). The majority of CTAB particles fall in the $4-8 \mathrm{~nm}$ range with a standard deviation of $3.6 \mathrm{~nm}$ and a mean of $7.0 \mathrm{~nm}$ (Figure S7). The majority of particles examined exhibit spherical morphology.

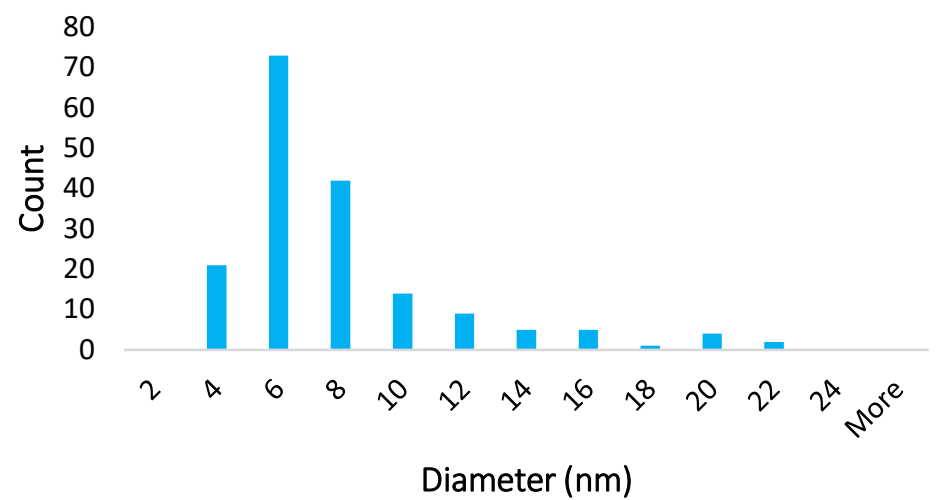

Figure S4. Histogram showing the distribution of CTAB capped AuNPs $(n=176)$.

DNA binding was analysed by DLS and UV-Vis (Fig. S6-S9) four solutions were prepared by diluting $1 \mathrm{~mL}$ of CTAB AuNPs in $10 \mathrm{~mL}$ deionised water $\left(0.01 \mathrm{mg} \mathrm{Au} \mathrm{mL}^{-1}\right) .2 \mathrm{~mL}$ of this solution was added to four vials, to three of the vials $5 \mu \mathrm{L}$ of $100 \mu \mathrm{M}$ DNA in deionised water; $\mathbf{0 S}, \mathbf{3 S}$ and $\mathbf{S H}$ were added respectively. 


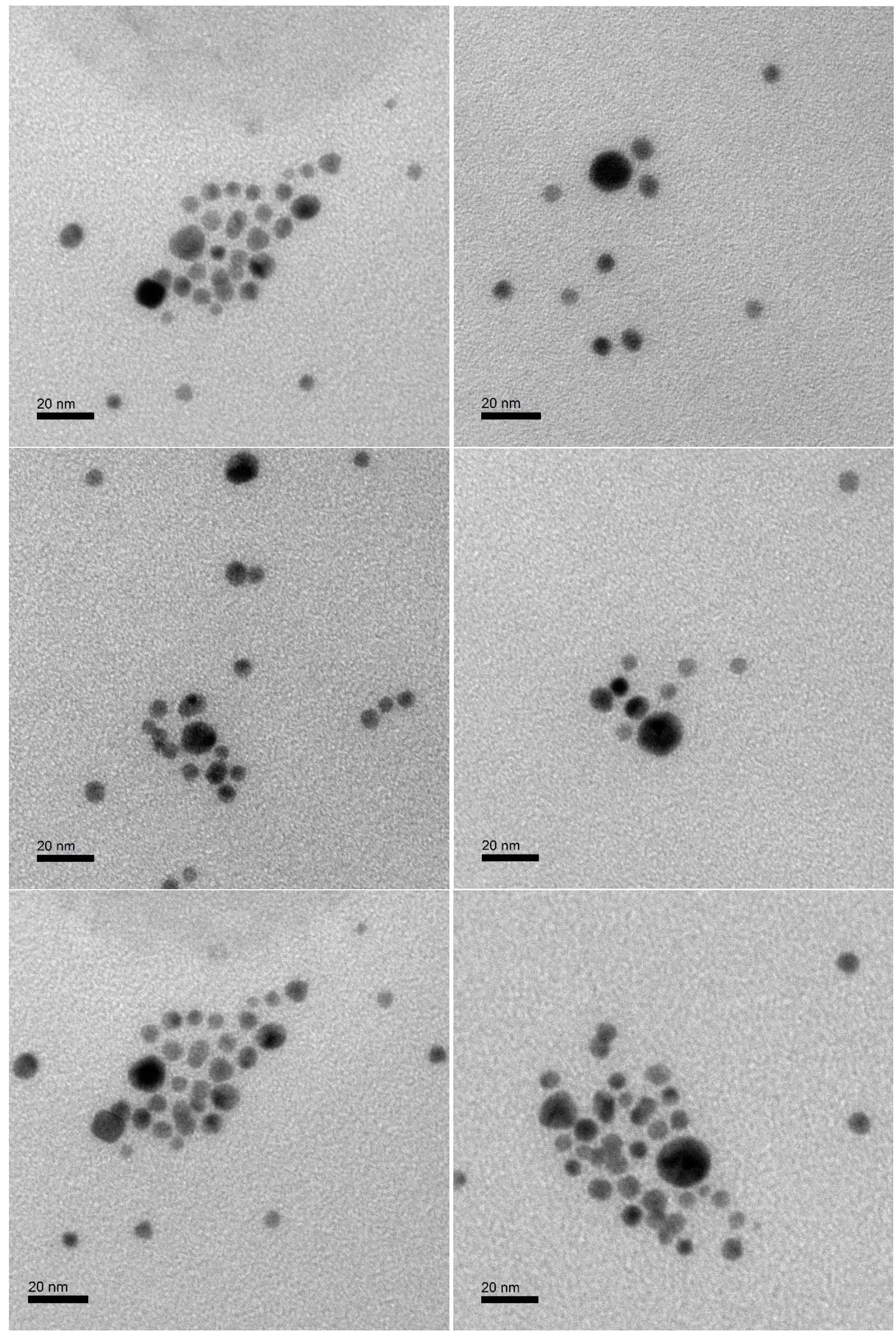

Figure S5. TEM images of CTAB AuNPs. 


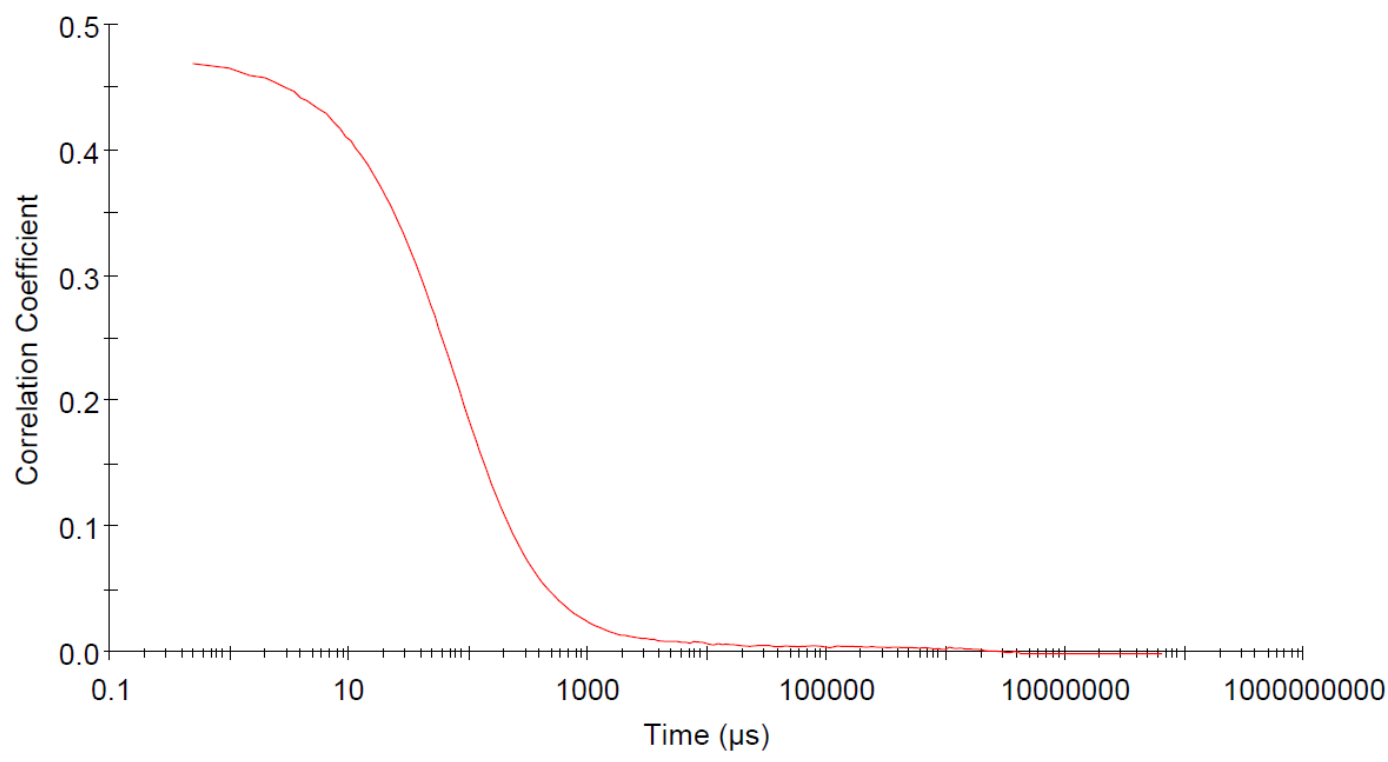

Figure S6. DLS correlogram of CTAB AuNPs.

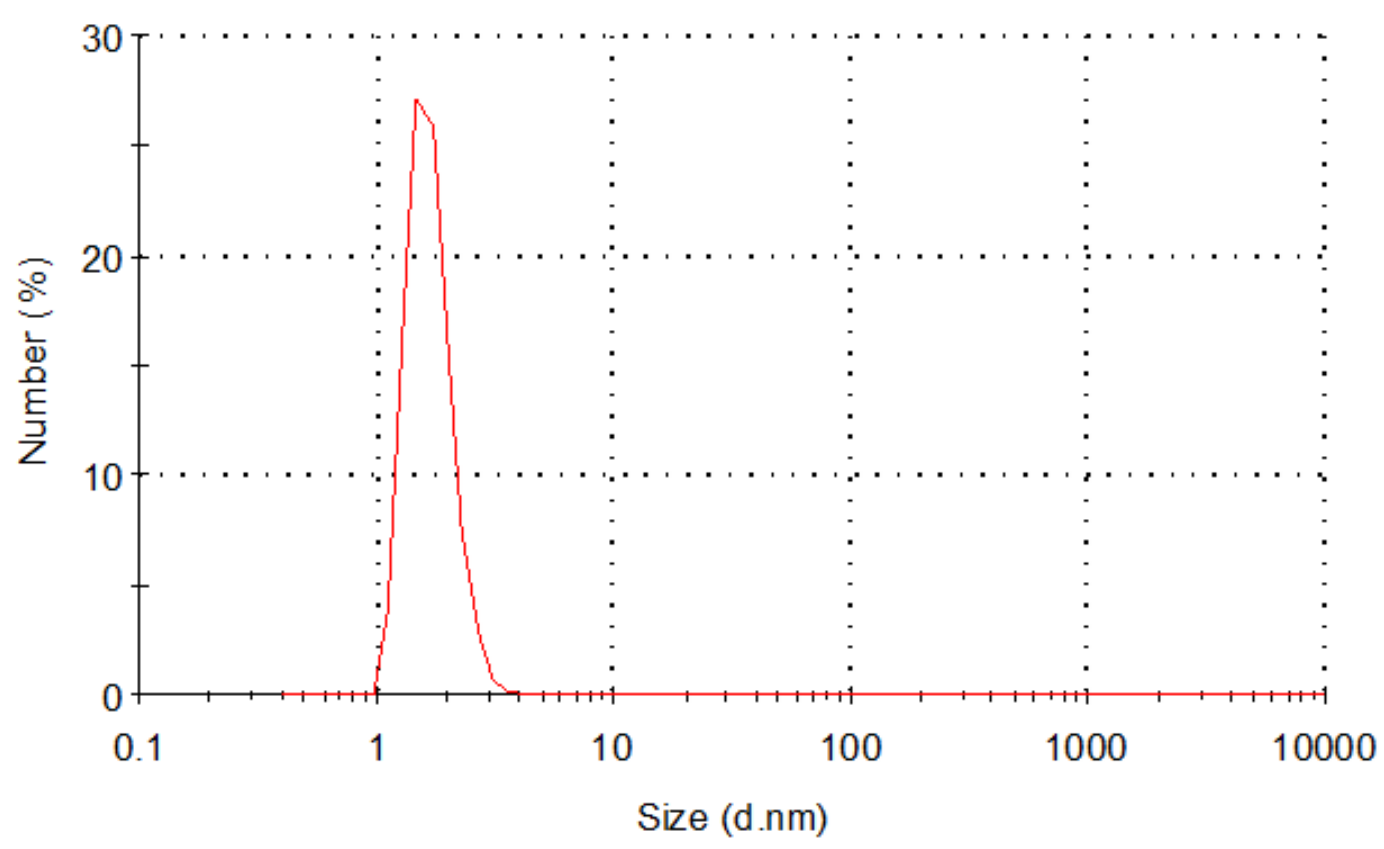

Figure S7. DLS size distribution by number of CTAB AuNPs. Apparent diameter $=1.5 \mathrm{~nm} \pm 0.38 \mathrm{~nm}$. 


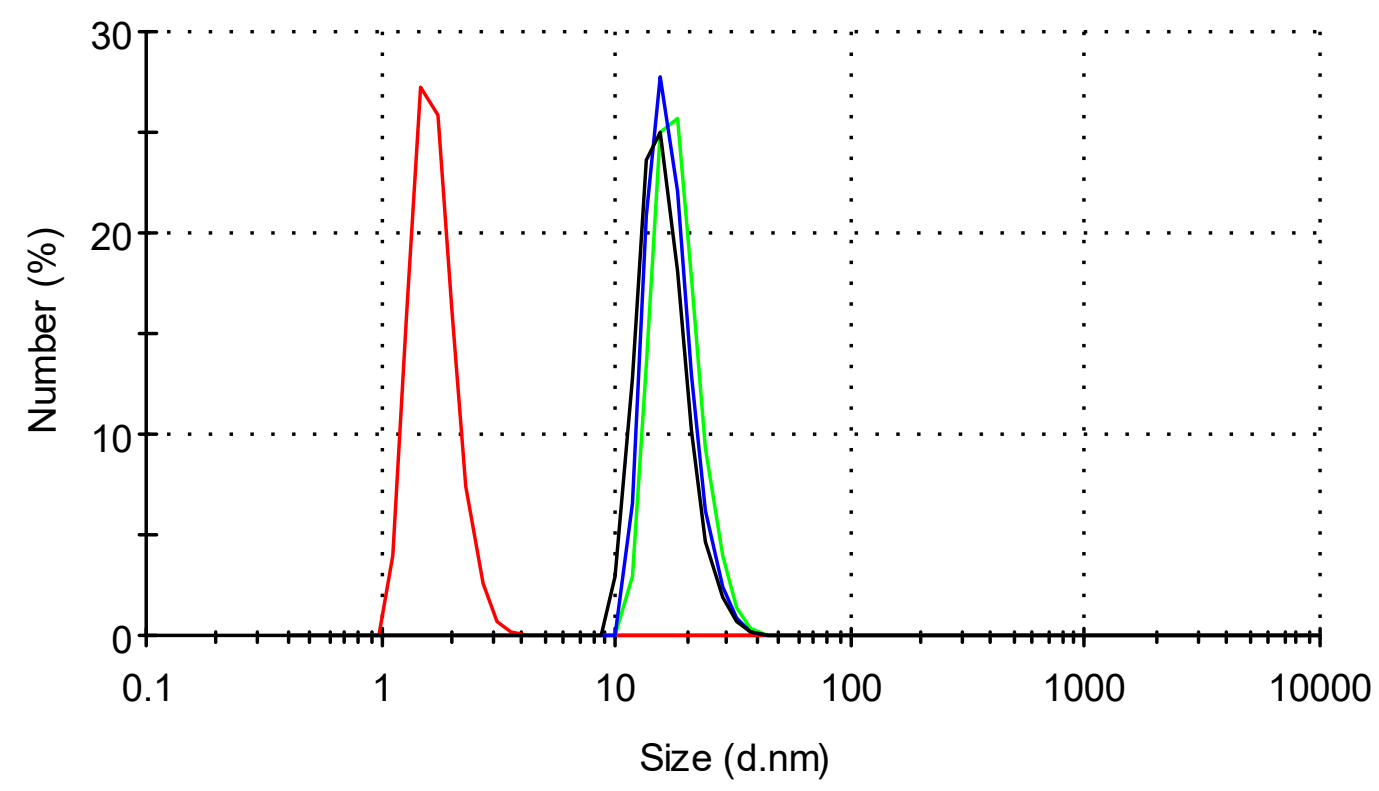

Figure S8. Size distribution by number of CTAB AuNPs - DNA binding affinity; CTAB AuNPs (red), OS (green), $3 S$ (blue), SH (black).
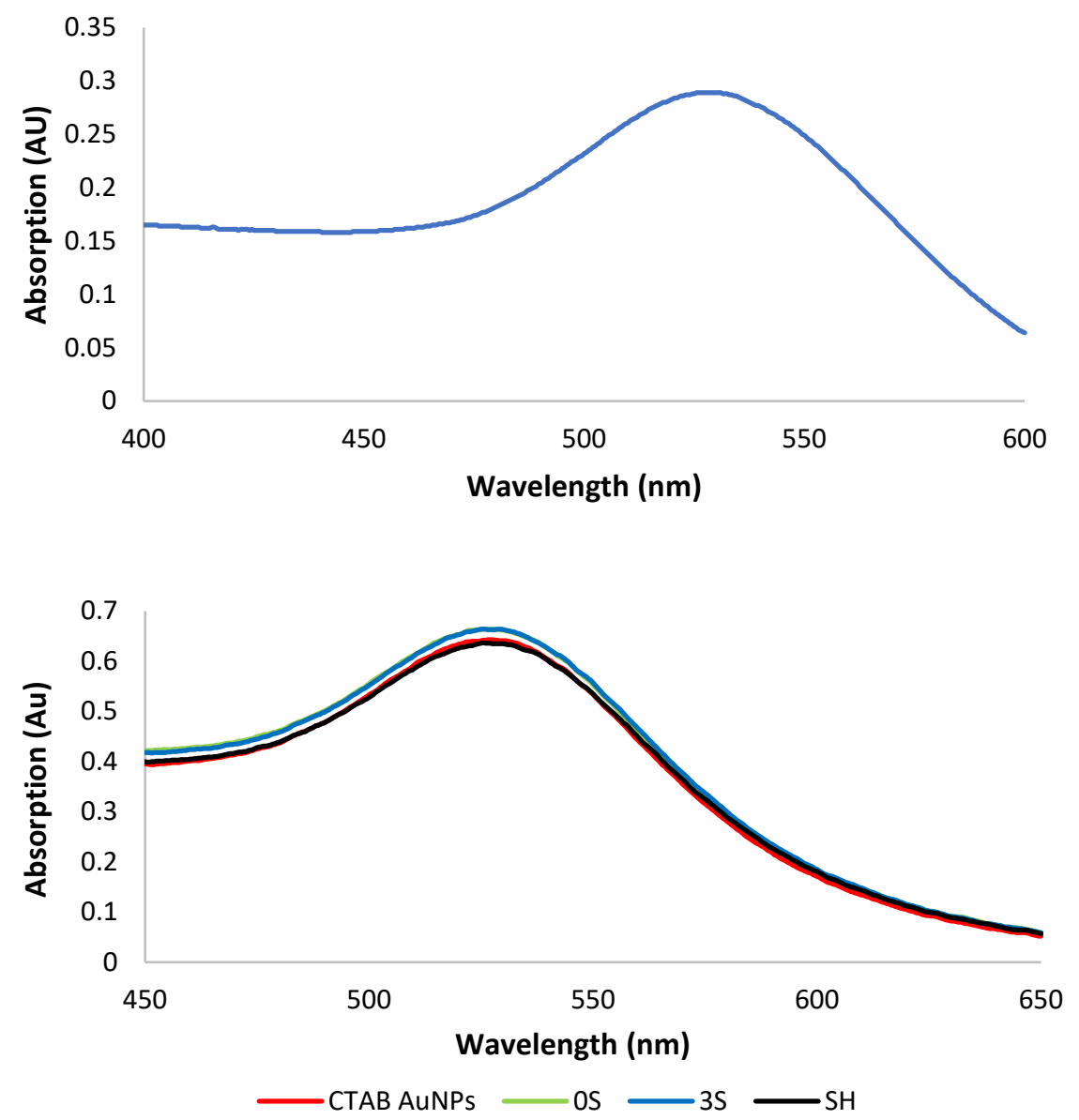

Figure S9. UV-visible spectrum of CTAB AuNPs (top). UV-visible spectrum of CTAB AuNPs - DNA binding affinity (bottom). 


\section{DMAP AuNPs}

DMAP-protected AuNPs were synthesised from precursor AuNPs, which were prepared by the Brust two phase method. ${ }^{4}$ Aliquat 336 was dissolved in toluene $(612 \mathrm{mg} / 20 \mathrm{~mL})$. An aqueous solution of hydrogen tetrachloroaurate $\left(\mathrm{HAuCl}_{4}\right)$ was prepared in deionised water $(100 \mathrm{mg}$ in $8 \mathrm{~mL})$. The two solutions were transferred to a round bottom flask and stirred for one hour. Transferring the biphasic mixture to a separating funnel allowed a distinct separation between the clear yellow organic phase and the creamy inorganic phase. The organic phase was transferred to a clean round bottom flask and a magnetic stir bar added. A fresh solution of sodium borohydride was prepared (109 $\mathrm{mg}$ in $6 \mathrm{~mL}$ ) in deionised water. The sodium borohydride was then added drop-wise to the stirring gold solution. A colour change was observed as the borohydride was added: yellow, to orange, and then to red. This was due to the reduction of $\mathrm{Au}^{\text {III }}$ to $\mathrm{Au}^{0}$. After two hours of stirring the solution was transferred to a separating funnel and the phases left to separate. The inorganic layer was removed and the organic layer was washed three times with $25 \mathrm{~mL}$ deionised water. A solution of 4-dimethylaminopyridine (DMAP) was prepared in deionised water ( $610 \mathrm{mg}$ in $50 \mathrm{~mL}$ ), the solution was then added to the separating funnel. The DMAP solution causes the nanoparticles to move into the aqueous phase by ligand substitution. DMAP AuNPs were stored in $50 \mathrm{~mL}$ falcon tubes at $4{ }^{\circ} \mathrm{C}$ at an approximate concentration of $2 \mathrm{mg} \mathrm{Au} \mathrm{mL}^{-1}$. The nanoparticles were stable for a minimum of two months.

Seventeen TEM images were captured of DMAP AuNPs (Fig. S14). The majority of DMAP particles fall in the $4-8 \mathrm{~nm}$ range with a standard deviation of $2.1 \mathrm{~nm}$ and a mean of $4.5 \mathrm{~nm}$ (Figure S10). The majority of particles examined exhibit spherical morphology. Clustering is likely due to a drying effect.

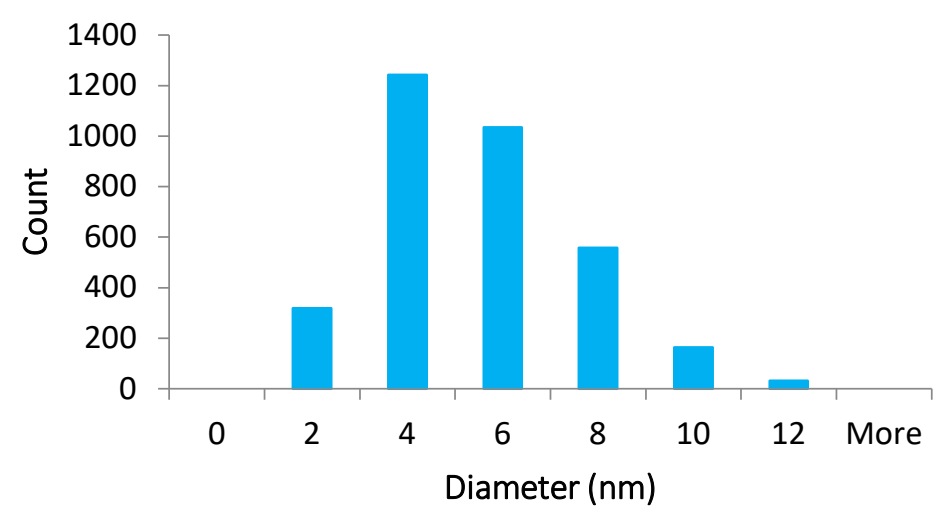

Figure S10. Histogram showing the distribution of DMAP capped AuNPs diameter ( $n=3347)$.

The samples for DLS and UV-Vis were prepared by diluting $40 \mu \mathrm{L}$ of DMAP AuNP stock solution in $2 \mathrm{~mL}$ deionised water. DNA binding was analysed by DLS and UV-Vis (Fig. S12-S15). Four solutions were prepared by diluting $1 \mathrm{~mL}$ of DMAP AuNPs in $10 \mathrm{~mL}$ deionised water $\left(0.1 \mathrm{mg} \mathrm{Au} \mathrm{mL}^{-1}\right) .2 \mathrm{~mL}$ of this solution was added to four vials, to three of the vials $5 \mu \mathrm{L}$ of $100 \mu \mathrm{M}$ DNA in deionised water; $\mathbf{0 S}, 35$ and SH were added respectively. 


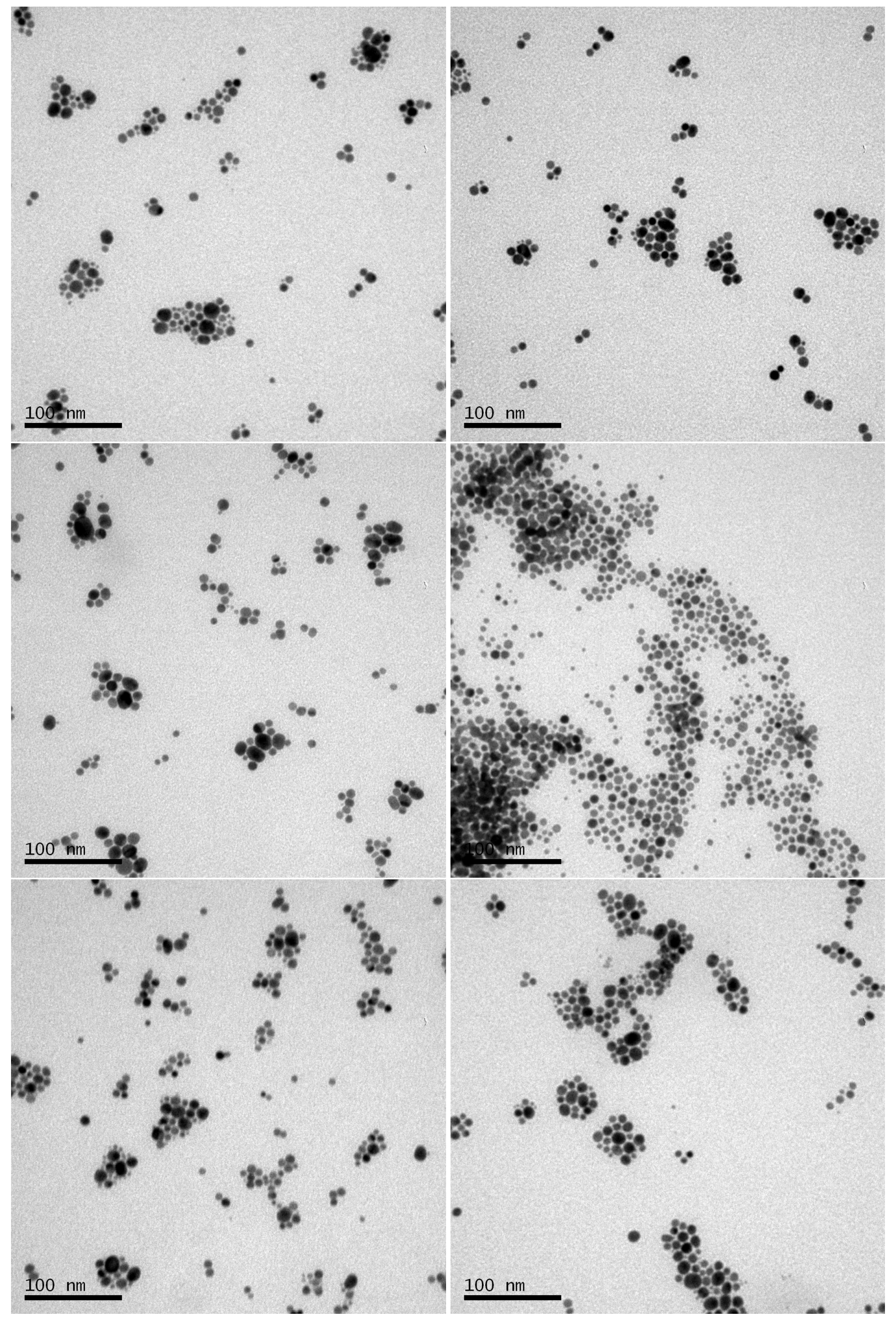

Figure S11. TEM images of DMAP AuNPs. 


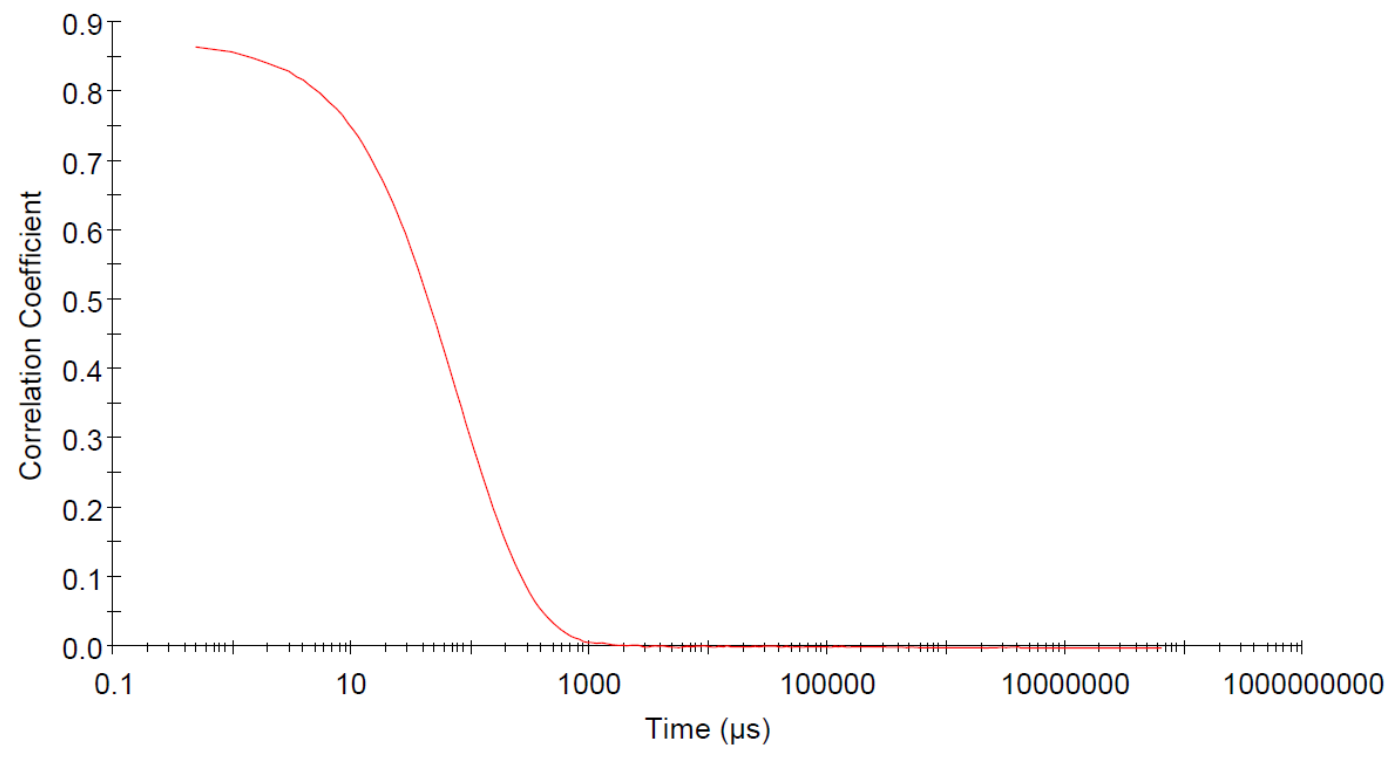

Figure S12. DLS correlogram of DMAP AuNPs.

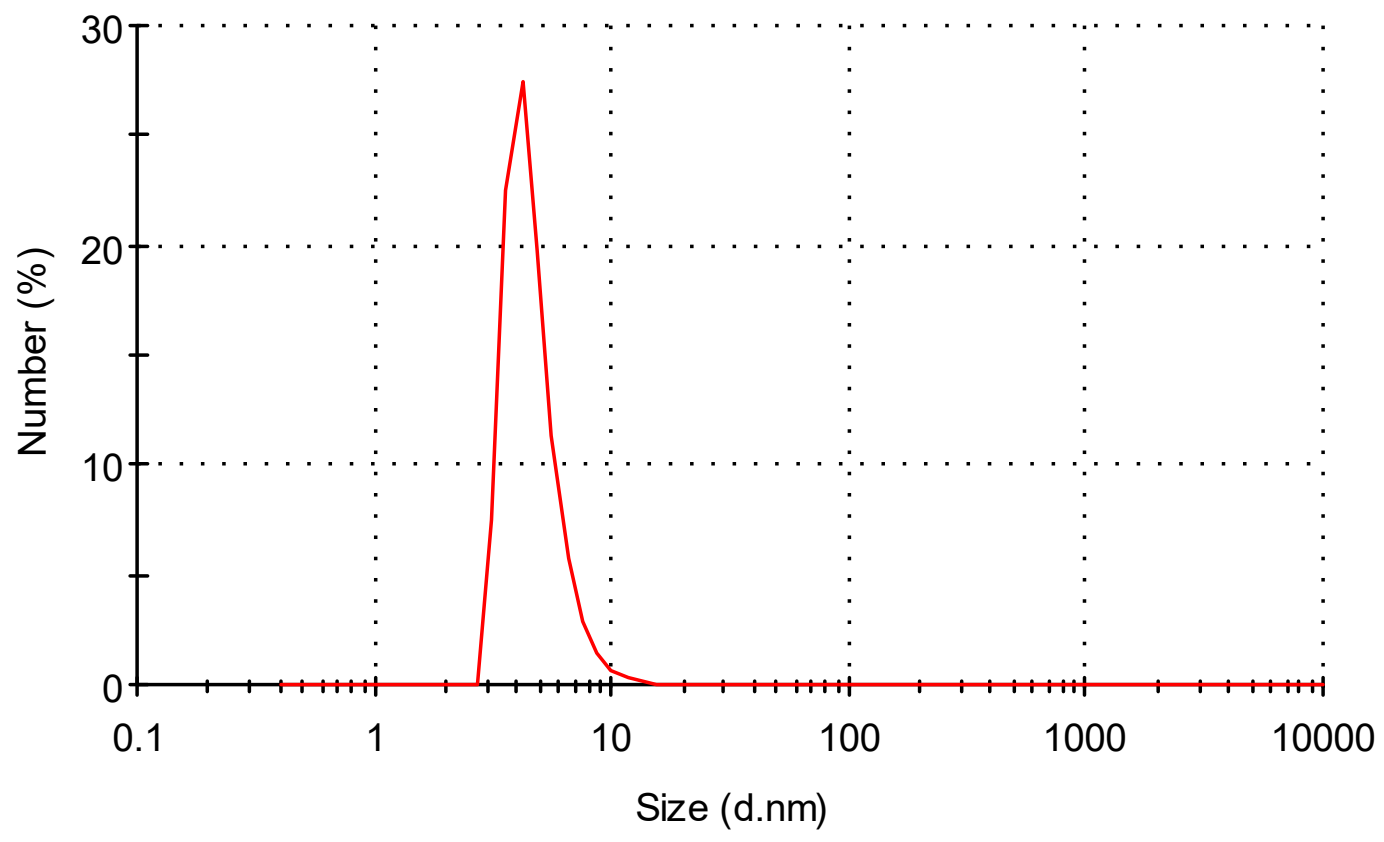

Figure S13. DLS size distribution by number of DMAP AuNPs. Diameter $=4.2 \mathrm{~nm} \pm 0.54 \mathrm{~nm}$. 


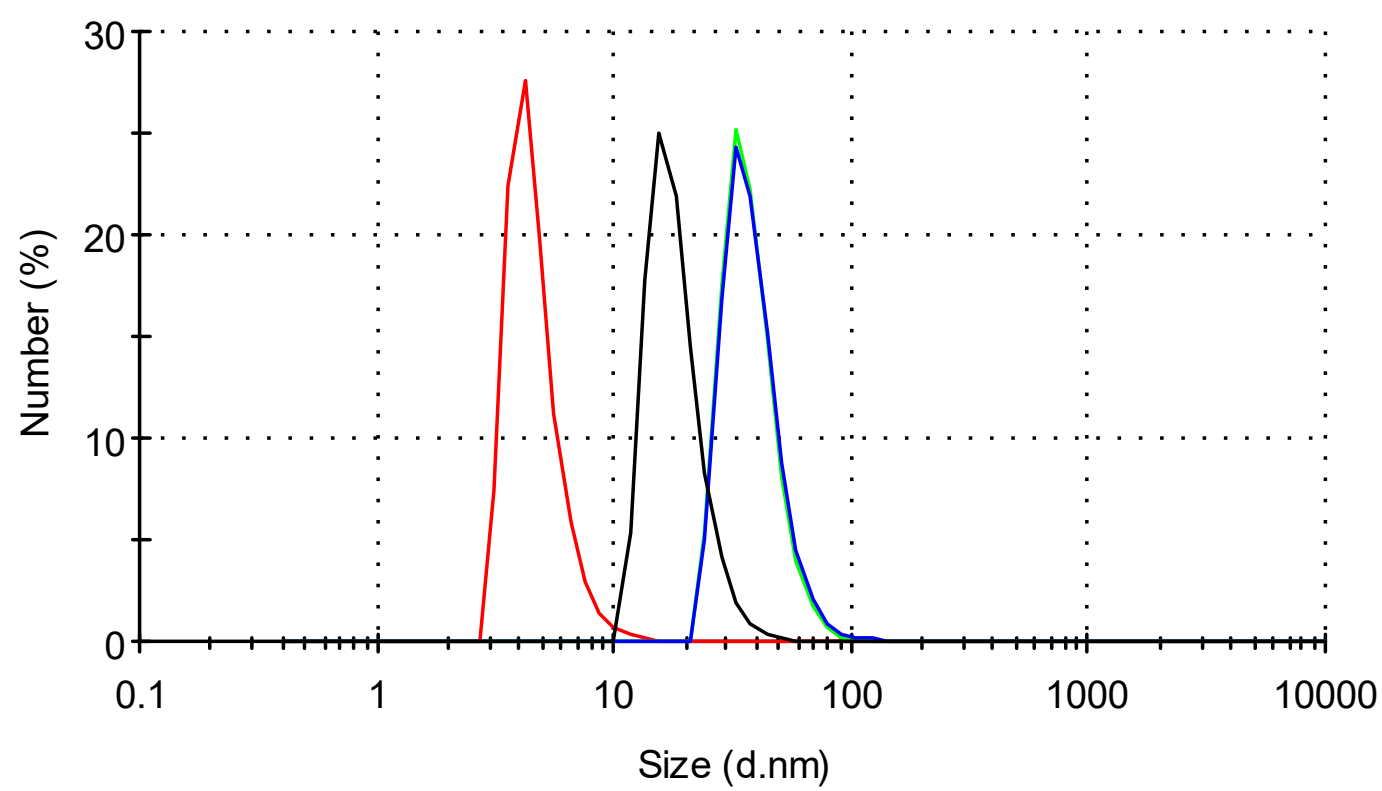

Figure S14. DLS size distribution by number of DMAP AuNPs - DNA binding affinity; DMAP AuNPs (red), OS (green), $3 \mathbf{S}$ (blue), SH (black).
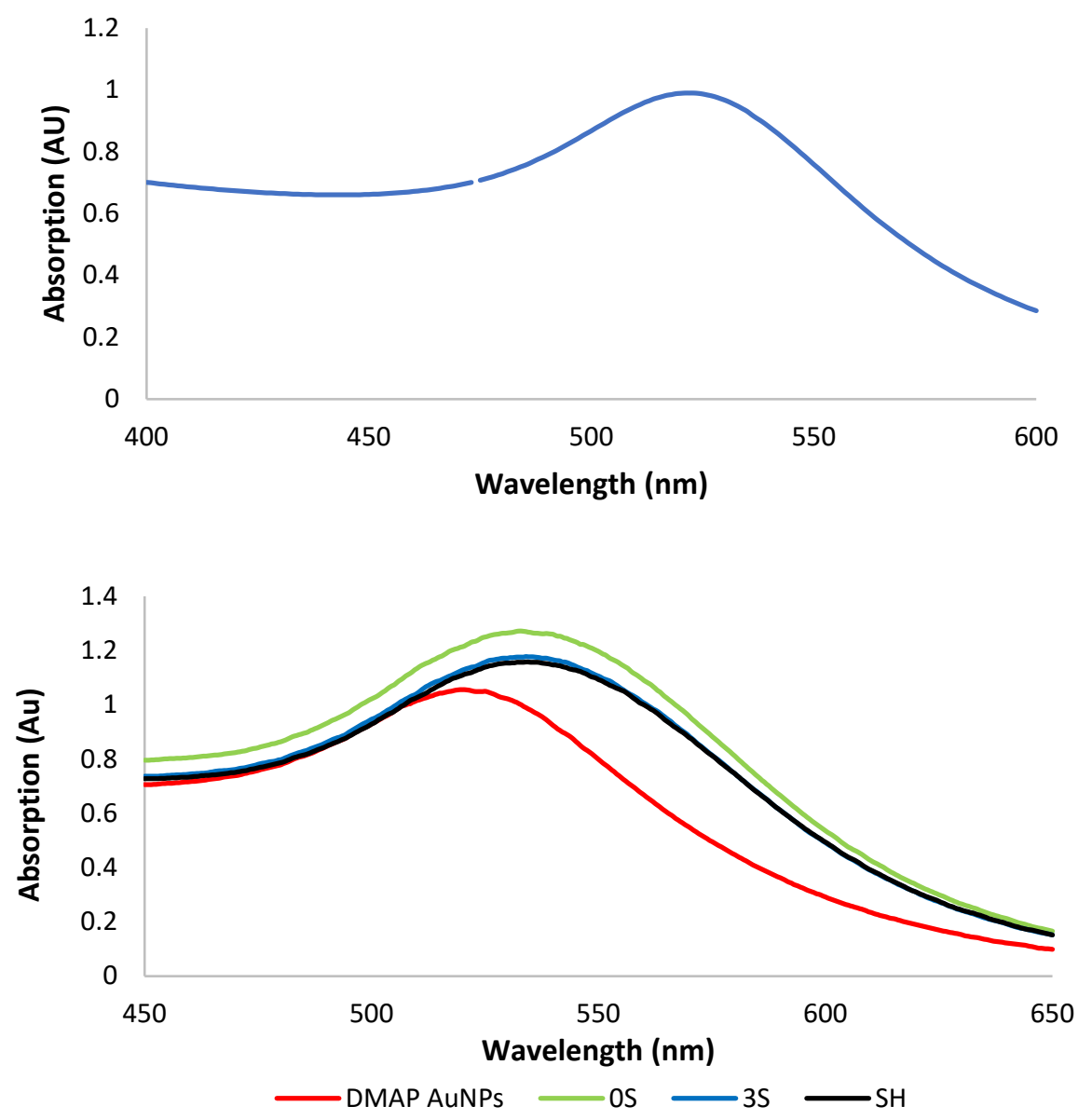

Figure S15. UV-visible spectrum of DMAP AuNPs (top). UV-visible spectrum of DMAP AuNPs - DNA binding affinity (bottom). 


\section{Gel casting and running methodology}

Gold nanoparticles were concentrated from the prepared stocks as follows:

\section{Citrate AuNPs}

Citrate AuNPs $\left(\approx 0.5 \mathrm{mg} \mathrm{Au} \mathrm{mL}^{-1}\right)$ were concentrated by centrifugation. $120 \mathrm{~mL}$ of citrate AuNPs were split into $1.5 \mathrm{~mL}$ aliquots. The aliquots were centrifuged at $1000 \mathrm{xg}$ for 10 minutes. A clear colourless supernatant and purple pellet were produced, the supernatant was discarded and the pellets collected and re-suspended in $1 \mathrm{~mL}$ deionised water $\left(\approx 60 \mathrm{mg} \mathrm{Au} \mathrm{mL}^{-1}\right)$.

\section{CTAB AuNPs}

CTAB AuNPs $\left(\approx 3.33 \mathrm{mg} \mathrm{Au} \mathrm{mL}^{-1}\right)$ were concentrated by evaporation followed by centrifugation. The solvent volume was reduced by one quarter, the nanoparticles were split into $500 \mu \mathrm{L}$ aliquots and $750 \mu \mathrm{L}$ of $100 \%$ $\mathrm{EtOH}$ was added. The centrifuge tubes were inverted and centrifuged at $1000 \mathrm{xg}$ for 3 minutes. The resultant supernatant was colourless and the pellet black in colour, the supernatant was discarded and the pellets collected and re-suspended in $1 \mathrm{~mL}$ deionised water $\left(\approx 50 \mathrm{mg} \mathrm{Au} \mathrm{mL}^{-1}\right)$.

\section{DMAP AuNPs}

DMAP AuNPs $\left(\approx 2 \mathrm{mg} \mathrm{Au} \mathrm{mL}^{-1}\right)$ were concentrated by ethanol precipitation. $30 \mathrm{~mL}$ of DMAP AuNPs was reduced in volume by two thirds by rotary evaporation at $70^{\circ} \mathrm{C}$. The solution was split into $500 \mu \mathrm{L}$ aliquots in $1.5 \mathrm{~mL}$ centrifuge tubes; to each $1 \mathrm{~mL}$ of $100 \% \mathrm{EtOH}$ was added. The tubes were inverted and centrifuged at $21,100 \times \mathrm{g}$ for 40 minutes. A clear ruby coloured supernatant and a dark red pellet were formed. The supernatant was removed and the pellets collected and re-suspended in $1 \mathrm{ml}$ deionised water $(\approx 60 \mathrm{mg} \mathrm{Au}$ $\left.\mathrm{mL}^{-1}\right)$.

\section{Casting and Running Gels}

\section{Oligonucleotide Gels:}

TBE denaturing polyacrylamide gels were prepared from a denaturing $20 \%$ polyacrylamide stock solution, the concentrated AuNP stock (when needed), and TBE buffer, with final concentrations of polyacrylamide as designated in the figures. Concentrations of citrate AuNPs in gels were tested between $1-60 \mathrm{mg} \mathrm{Au} \mathrm{mL}^{-1}$. Concentrations of CTAB AuNPs were tested between $1-10 \mathrm{mg} \mathrm{Au} \mathrm{mL}^{-1}$. Concentrations of DMAP AuNPs were tested between 3-12 mg Au mL $\mathrm{mL}^{-1}$.

The gels were polymerised by addition of TEMED ( $1 \mu \mathrm{L}$ for each $\mathrm{mL}$ of gel) followed by APS ( $40 \%$ stock, 4.3 $\mu \mathrm{L}$ per $\mathrm{mL}(2 \mu \mathrm{L}$ per $\mathrm{mL}$ for mini gels) of non-gold gel, $5 \mu \mathrm{L}$ per $\mathrm{mL}(2.3 \mu \mathrm{L}$ per $\mathrm{mL}$ for mini gels) of gold gel). The solution was mixed thoroughly and poured between glass plates with $0.75 \mathrm{~mm}$ ( $0.1 \mathrm{~mm}$ for mini gels) spacers, followed by insertion of a $0.75 \mathrm{~mm}(0.1 \mathrm{~mm}$ for mini gels) comb. The gel was then left to fully polymerise. Approximately $80 \%$ of the cassette was filled with non-Au gel solution, and the remainder completed with AuNP gel solution after the first layer had set. The comb was removed after polymerisation and the wells were flushed with deionised water, and then buffer. TAMg gels were prepared analogously.

Electrophoresis samples were prepared as follows; $1 \mu \mathrm{L}$ of $100 \mathrm{mM}$ stock DNA was diluted in $20 \mu \mathrm{L}$ of $8 \mathrm{M}$ urea and $20 \mu \mathrm{L}$ deionised water. $20 \mu \mathrm{L}$ of each sample (10 $\mu \mathrm{L}$ for mini gels) was loaded onto the polyacrylamide gel.

All gels were run at maximum voltage (up to $300 \mathrm{~V}$ ), $15 \mathrm{~mA}$, for 90 minutes ( 25 minutes for mini gels). Gels were stained in Stains-All prepared in isopropanol-tris buffer, for a minimum of 30 minutes; the gels were then rinsed of excess stain using water before being imaged on an Epson scanner. Images were digitally manipulated using Adobe Photoshop CC only to crop, adjust contrast, and optimise greyscale output. 


\section{Protein Mini Gels:}

Gel solutions were prepared from $30 \%$ polyacrylamide stock solution and $0.375 \mathrm{M}$ tris buffer for the resolving gel $(10 \%$ and $15 \%)$, the $\mathrm{Au}$ - resolving gel (10\%) and the stacking gel (4\%). The Au + resolving gel was prepared from $30 \%$ polyacrylamide stock solution and $1.5 \mathrm{M}$ tris buffer to a concentration of $10 \%$ with the addition of $2.5 \mathrm{mgmL}^{-1}$ of DMAP AuNPs. The main resolving gel was a gradient gel, produced by combining equal volumes of $10 \%$ and $15 \%$ acrylamide solution. Mixing was introduced by the introduction of an air bubble into the pipette, the solution was deposited into the cassettes to approximately $80 \%$ of the cassette height. The gel was left to fully polymerise. $10 \%$ of the remaining cassette was filled with either $\mathrm{Au}+$ or $\mathrm{Au}$ $-10 \%$ acrylamide and left to fully polymerise before the remainder was filled with $4 \%$ stacking gel. The comb was inserted and the stacking gel left to polymerise fully.

Electrophoresis samples were prepared as follows; $15 \mu \mathrm{L}$ of protein sample was added to $10 \mu \mathrm{L} 10 \% \mathrm{~N}$ ethylmaleimide (NEM) in $4 x$ loading dye (Bromophenol Blue). $12.5 \mu \mathrm{L}$ was loaded onto the polyacrylamide.

All gels were run at $160 \mathrm{~V}$ for 1 hour. The gels were stained in Expedeon Instant Blue overnight while rocking. Gels were imaged on an Epson Perfection 3200 scanner with Epson Scan 3.04 software. Images were digitally manipulated using Adobe Photoshop CC only to crop, adjust contrast, and optimise greyscale output.

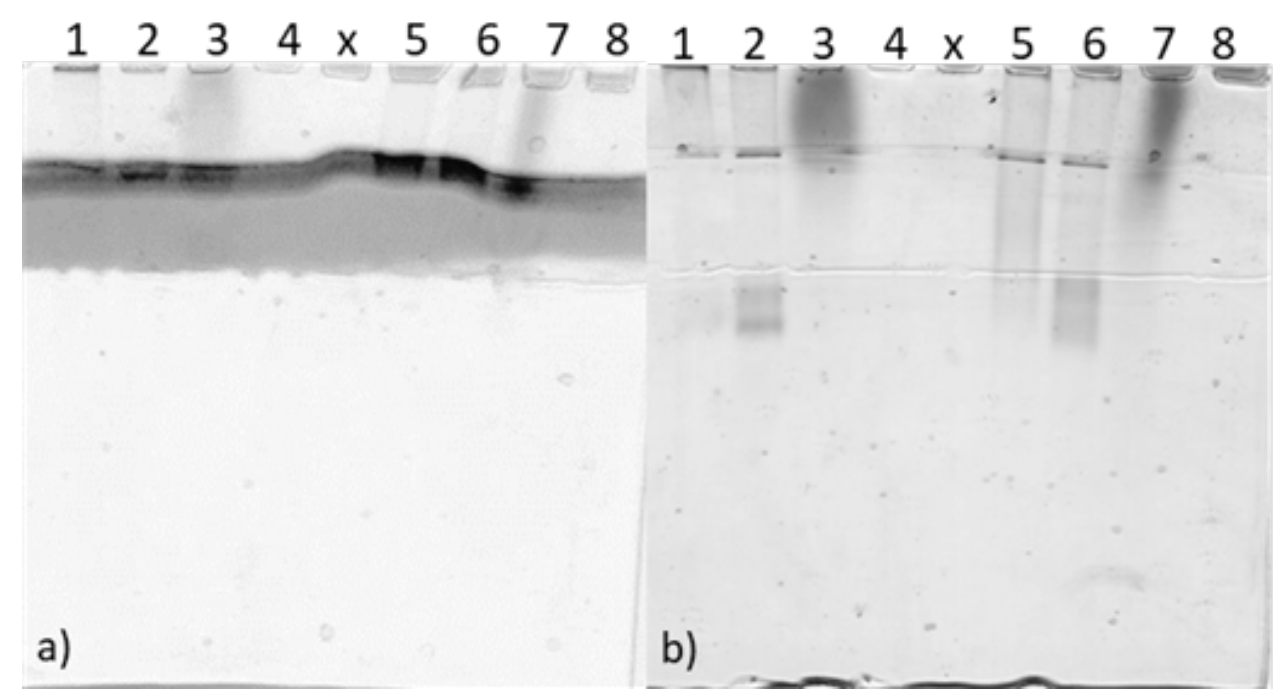

Figure S16. (a) Gold-PAGE Protein gel using DMAP AuNPs (2.5 $\left.\mathrm{mgmL}^{-1}\right)$. Stacking gel (4 \%), AuNP + resolving gel (10\%) and resolving gradient gel (10-15\%). (b) Protein gel without DMAP AuNPs. Stacking gel (4\%), AuNP - resolving gel (10\%) and resolving gradient gel (10-15\%). Lanes: $1=$ RNAse + NEM, 2 = BSA + NEM, 3 = BSA + NEM, $4=$ Lys + NEM, $5=$ RNAse, $6=$ BSA, $7=$ BSA, 8 = Lys. $x=$ unused. All gels were ran in native conditions in Tris- $\mathrm{HCl}$ buffer at room temperature.

During studies using proteins complete retention of the larger more negative proteins was observed on every occasion. However issues with the visualisation of Lysozyme was a problem, we believe this to be due to it containing more positive residues than the other proteins. Further development of the method is required in order to achieve greater sensitivity between proteins of different sizes and sulphur content. 


\section{Rheology}

Slab gels based on TBE buffer were prepared as described above, and after full polymerisation, sections were cut out for rheometric experiments. AuNPs, where used, were DMAP stabilised, at $3 \mathrm{mg} \mathrm{Au} \mathrm{mL}^{-1}$.

The platform was held at $25^{\circ} \mathrm{C}$. Experiments were run for 5 minutes, with a wait time of 5 minutes.

Amplitude Sweep parameters:

- $\quad$ LVER region limit $3 \%$

- (x axis) Variable sheer strain, all default

- (y axis) Variable G' storage modulus, all default

- Sheer strain oscillating amplitude gamma: 0.01-10\%

- 25 points measured

Frequency Sweep parameters:

- Tolerance: 0.03

- Smoothing range: 0.01

- Angular frequency: 10 rads $^{-1}$

- Oscillating gamma sheer strain: $0.1 \%$

- 18 points measured

The first investigation of the samples was an amplitude sweep, which was used to establish the linear viscoelastic range (LVER) for each sample; this allows us to set the parameters for the frequency experiment, as these can only be carried out in the LVER. The amplitude sweep is an investigation of sheer strain as a function of the storage modulus $\left(G^{\prime}\right)$ and its exponential function the loss modulus $\left(G^{\prime \prime}\right)^{5}$. $G^{\prime}$ denotes how viscous a gel is and $\mathrm{G}^{\prime \prime}$ denotes the elasticity of the gel.

As can be seen from Figures S19-S25 there appears to be a small amount of difference between the storage moduli for the gel with and without gold, but the loss modulus is in general lower. Adding gold to the gel appears to extend the LVER. This trend can be seen across concentrations from $5-20 \%$ acrylamide, which are those typically used in electrophoresis experiments. As would be expected, both $\mathrm{G}^{\prime}$ and $\mathrm{G}^{\prime \prime}$ increased with polyacrylamide concentration. The LVERs for gels without gold were: $5 \%-3 \mathrm{~Pa}, 10 \%-0.2 \mathrm{~Pa}, 12 \%-0.1$ $\mathrm{Pa}, 15 \%-0.1 \mathrm{~Pa}$ and $20 \%-0.04 \mathrm{~Pa}$. The LVERs for gels containing gold were: $5 \%$ - $3 \mathrm{~Pa}, 10 \%-0.2 \mathrm{~Pa}, 12 \%$ - $0.06 \mathrm{~Pa}, 15 \%-0.03 \mathrm{~Pa}$ and $20 \%-0.03 \mathrm{~Pa}$. These strain values were used to set the parameters for the frequency sweep experiments. 


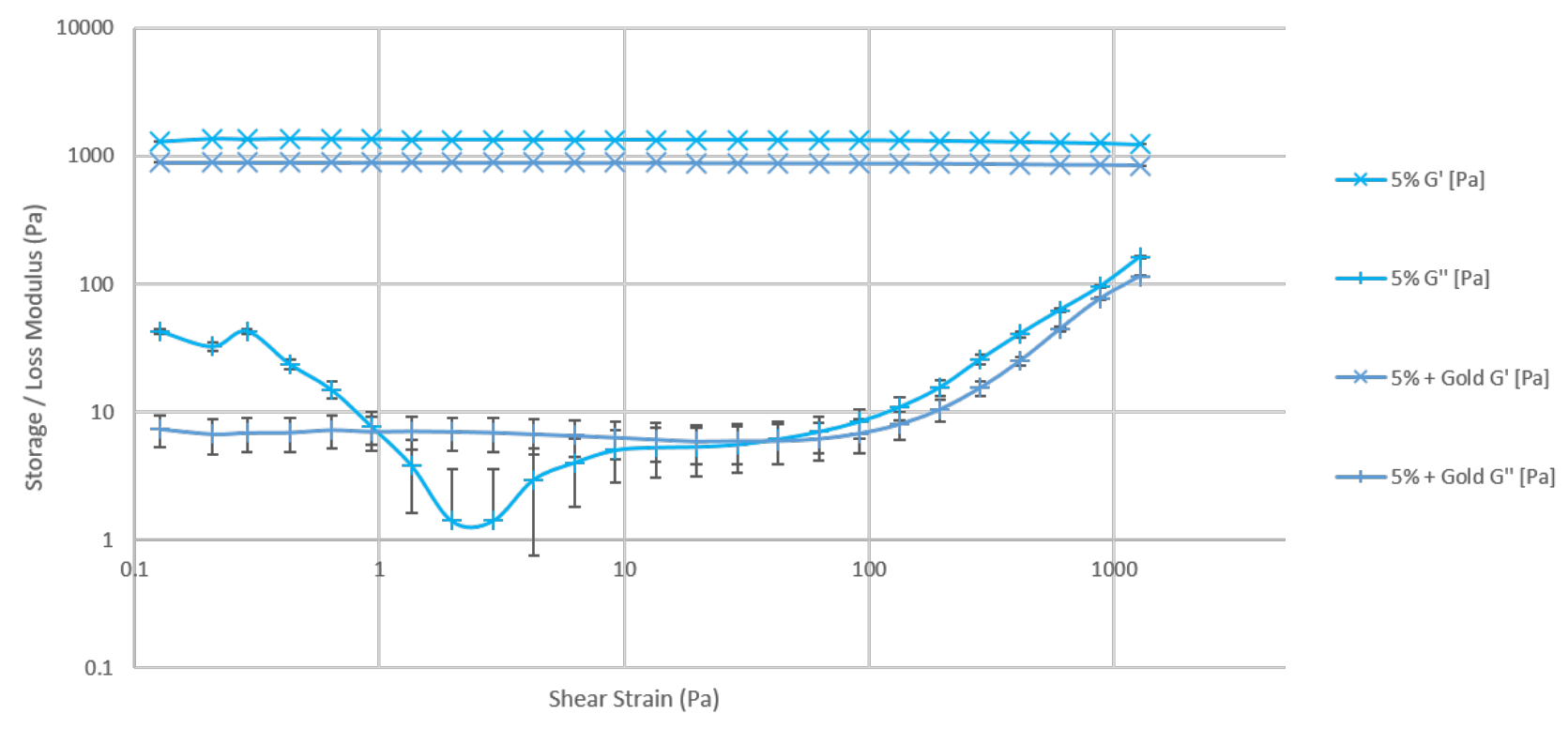

Figure S17. Comparison of average amplitude sweep data for $5 \%$ polyacrylamide with and without gold. Error bars represent the Log spread of data.

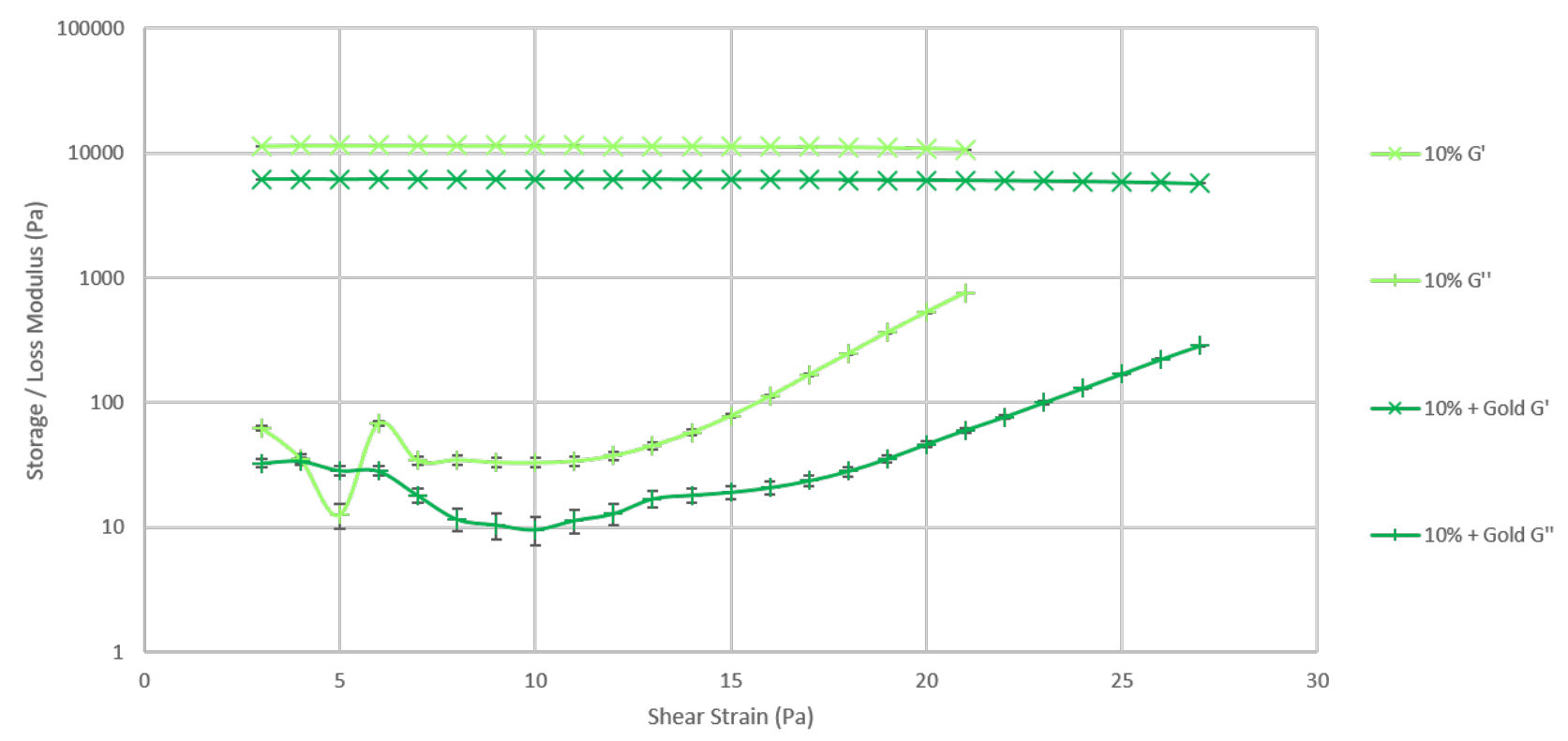

Figure S18. Comparison of average amplitude sweep data for $10 \%$ polyacrylamide with and without gold. Error bars represent the Log spread of data. 


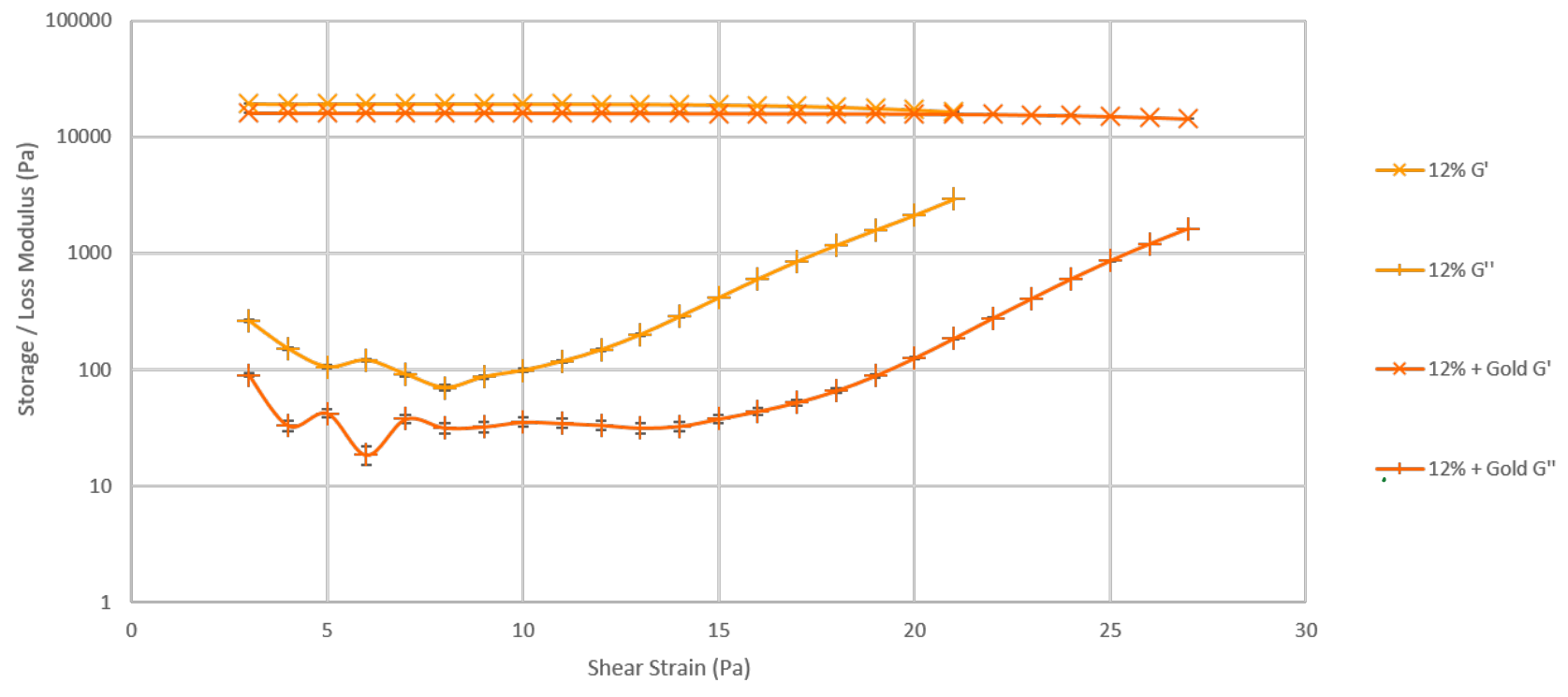

Figure S19. Comparison of average amplitude sweep data for $12 \%$ polyacrylamide with and without gold. Error bars represent the Log spread of data.

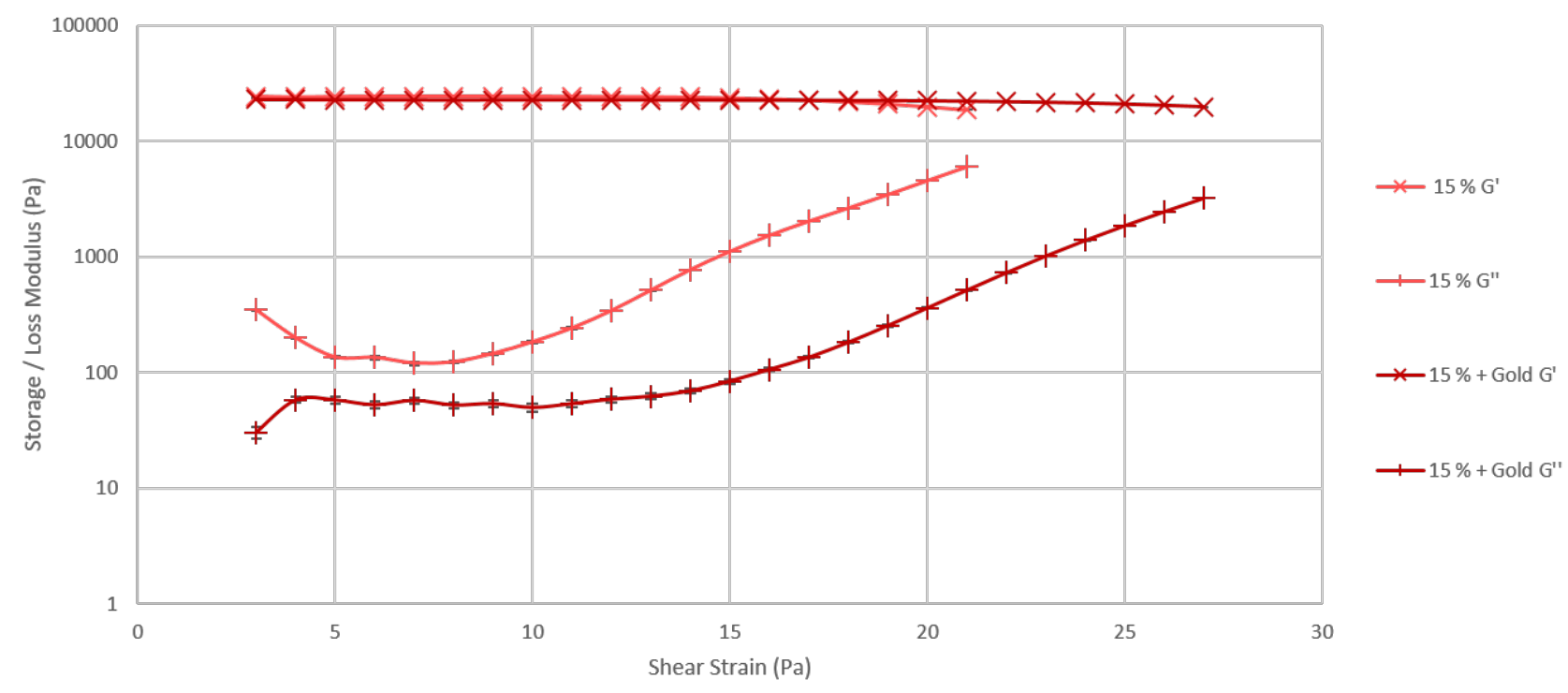

Figure S20. Comparison of average amplitude sweep data for $15 \%$ polyacrylamide with and without gold. Error bars represent the Log spread of data. 


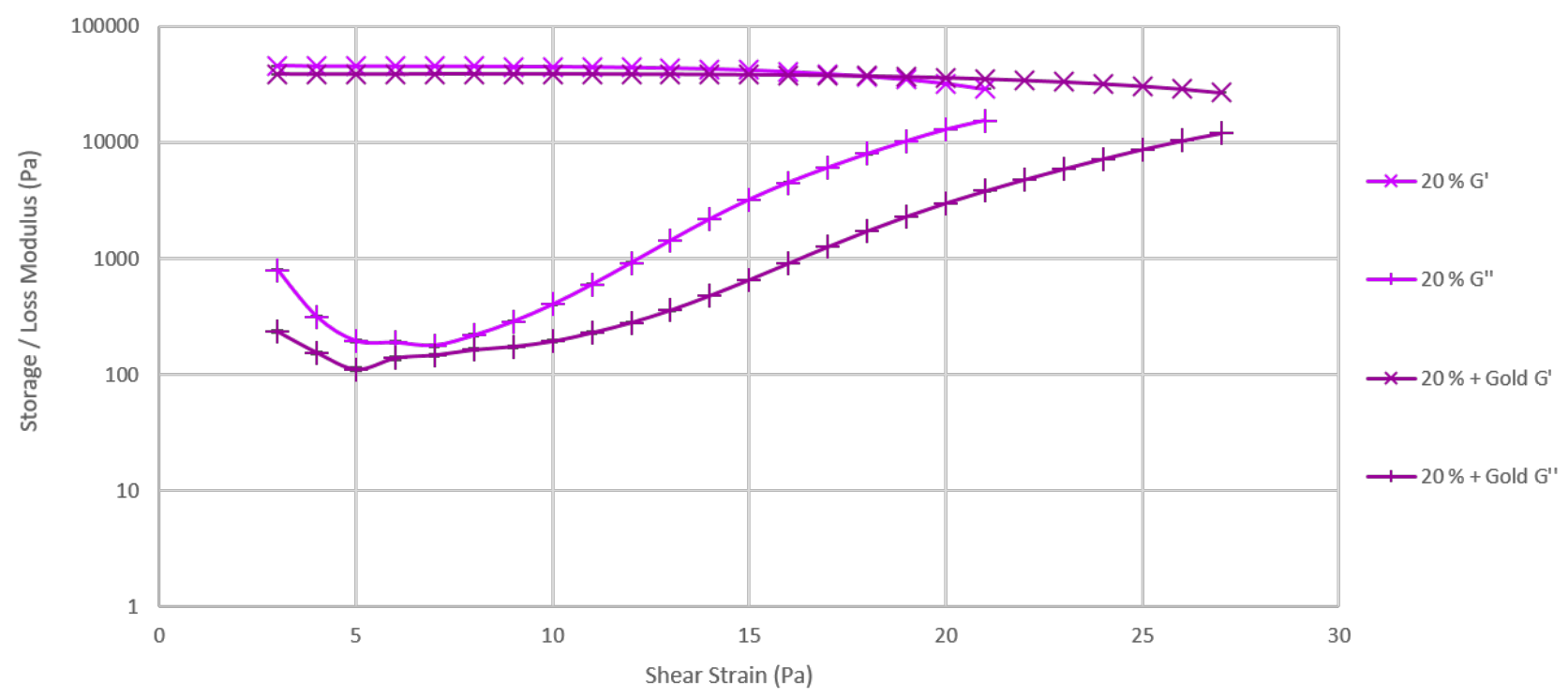

Figure S21. Comparison of average amplitude sweep data for $20 \%$ polyacrylamide with and without gold. Error bars represent the Log spread of data.

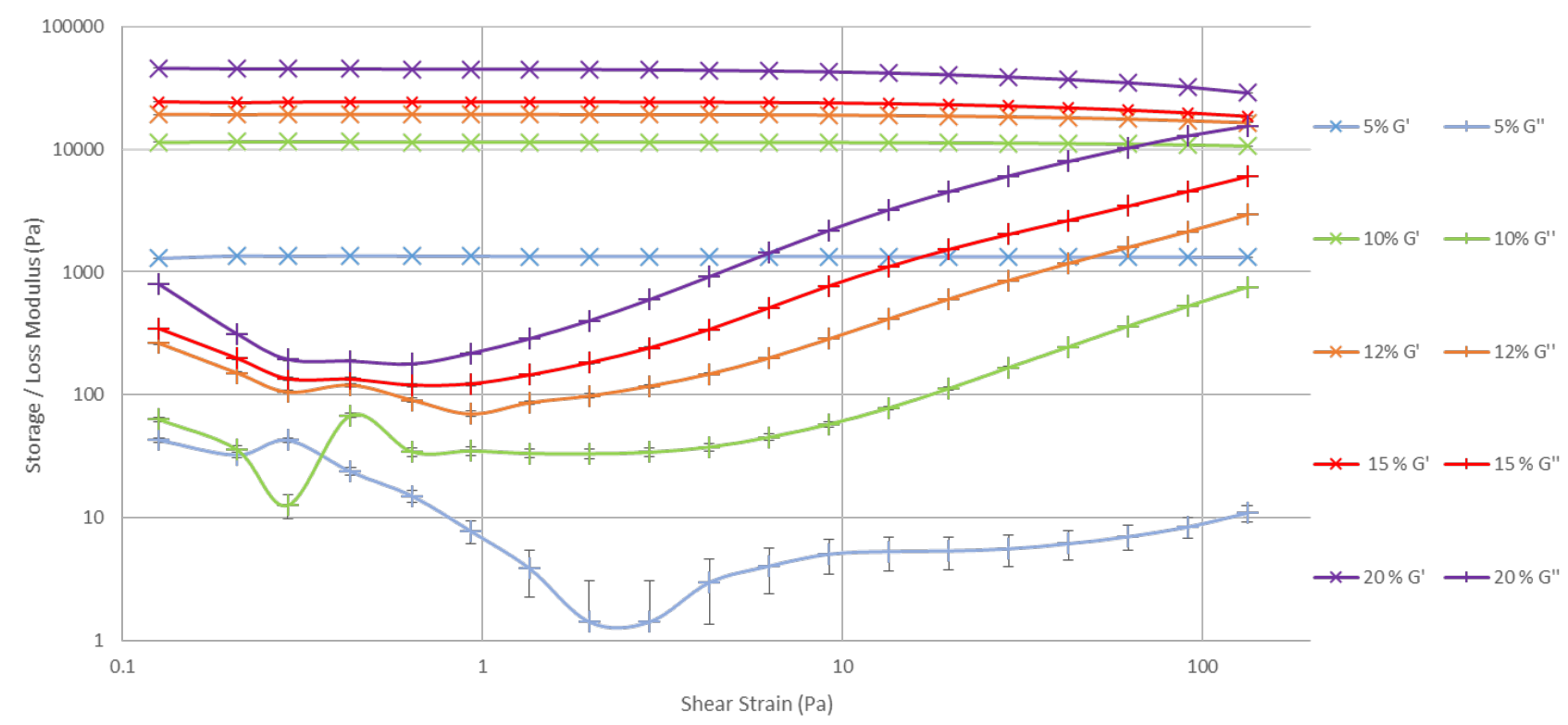

Figure S22. Averaged amplitude sweep rheology data for polyacrylamide gel without gold, for percentages; $5,10,12,15$ and $20 \%$. Error bars depict the Log spread of data. 


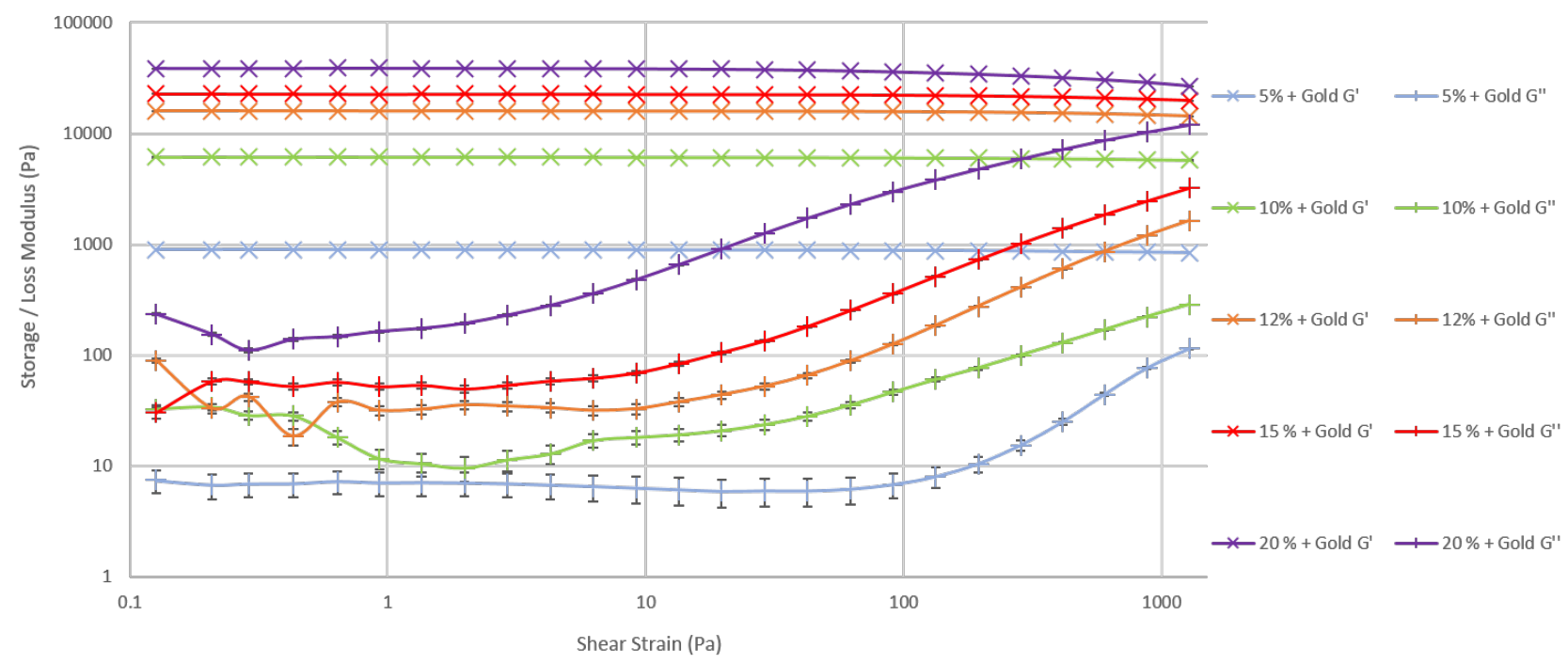

Figure S23. Average amplitude sweep rheology data for polyacrylamide gel with gold, for percentages; 5, 10, 12, 15 and $20 \%$. Error bars depict the Log spread of data.

Frequency sweep experiments were then performed on samples from the same slabs, with data shown in Figures S26-S32. In general, the storage moduli of gels was unchanged by the presence of the AuNPs, but the loss modulus was lowered. In some cases, the gold gave improved quantitative repeatability when the same sample was re-measured, suggesting that it recovers better from stress.

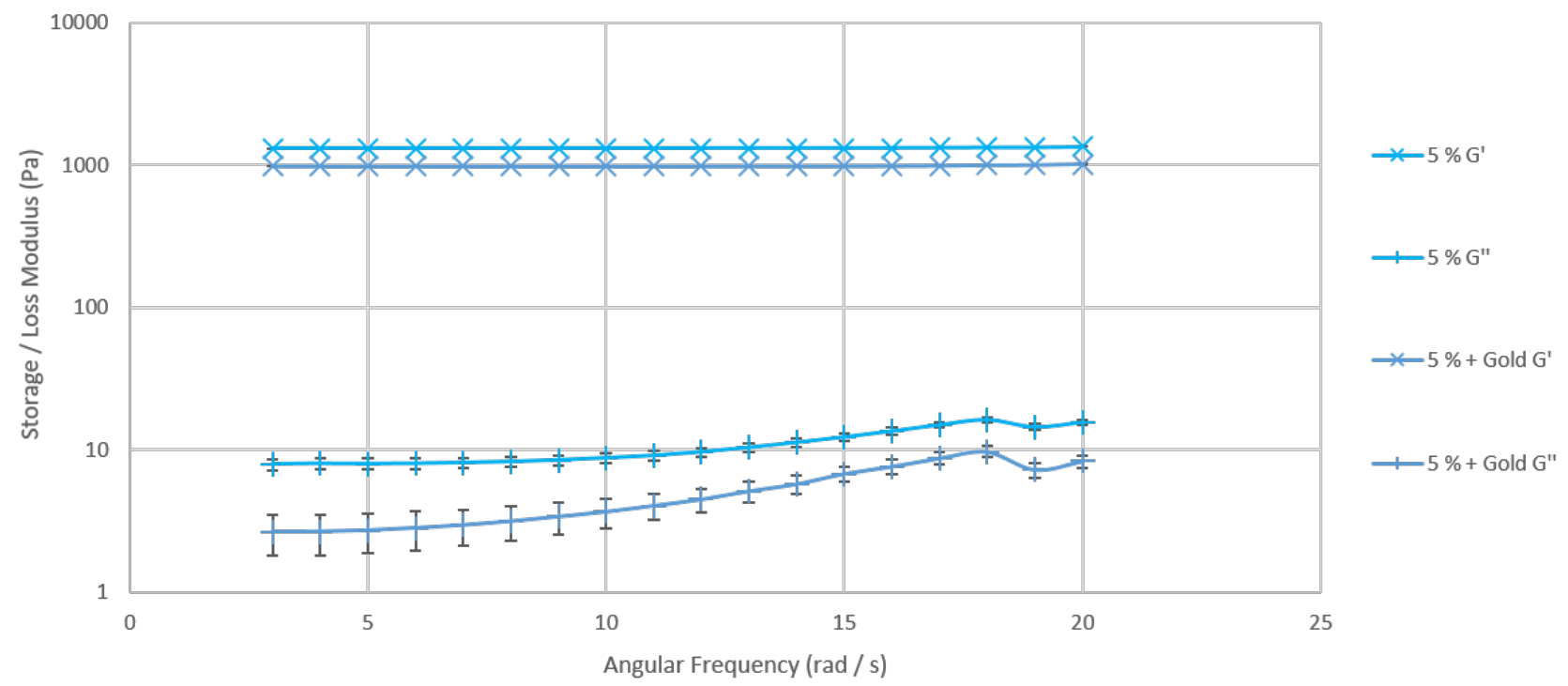

Figure S24 Comparison of average frequency sweep data for $5 \%$ polyacrylamide with and without gold. Error bars represent the Log spread of data. 


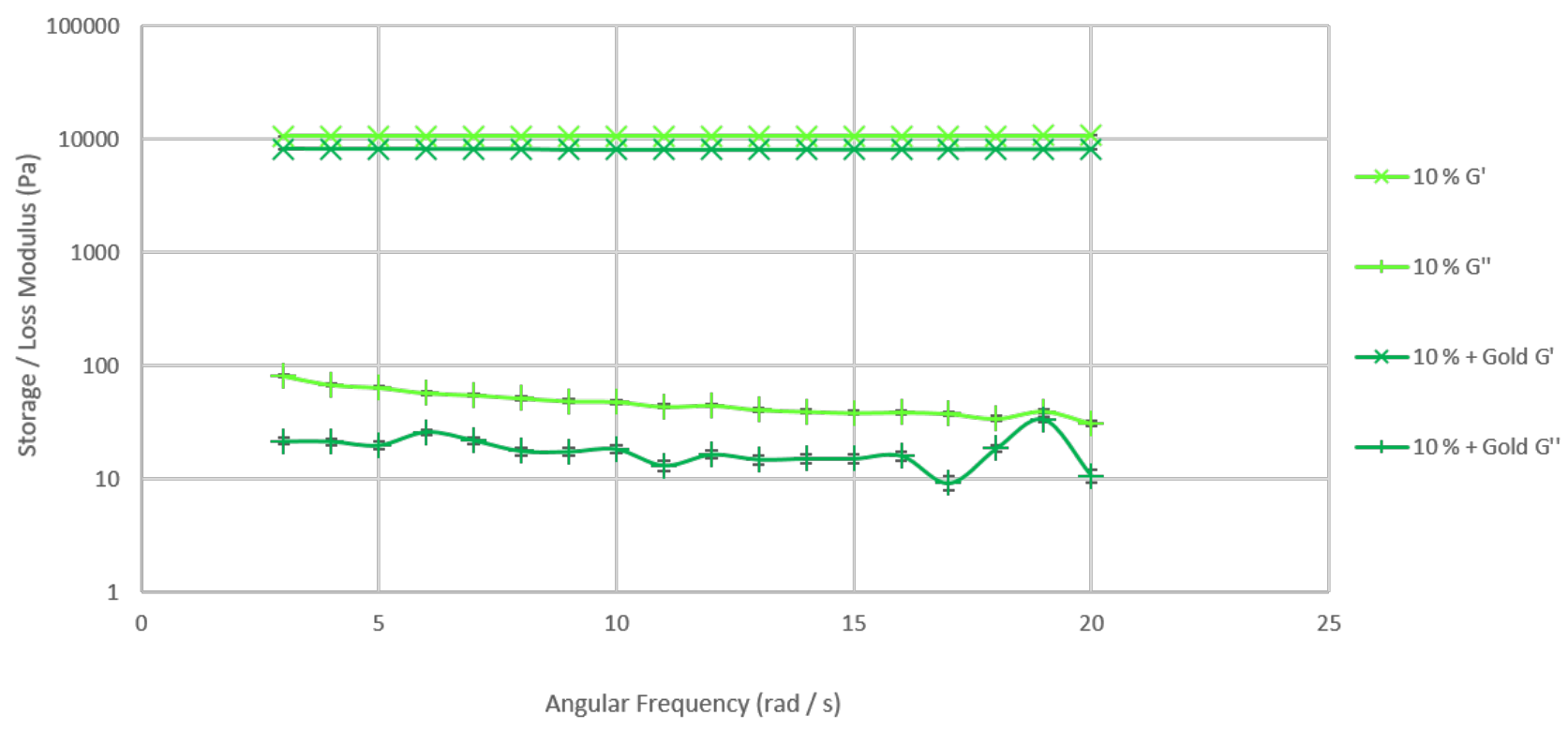

Figure S25. Comparison of average frequency sweep data for $10 \%$ polyacrylamide with and without gold. Error bars represent the Log spread of data.

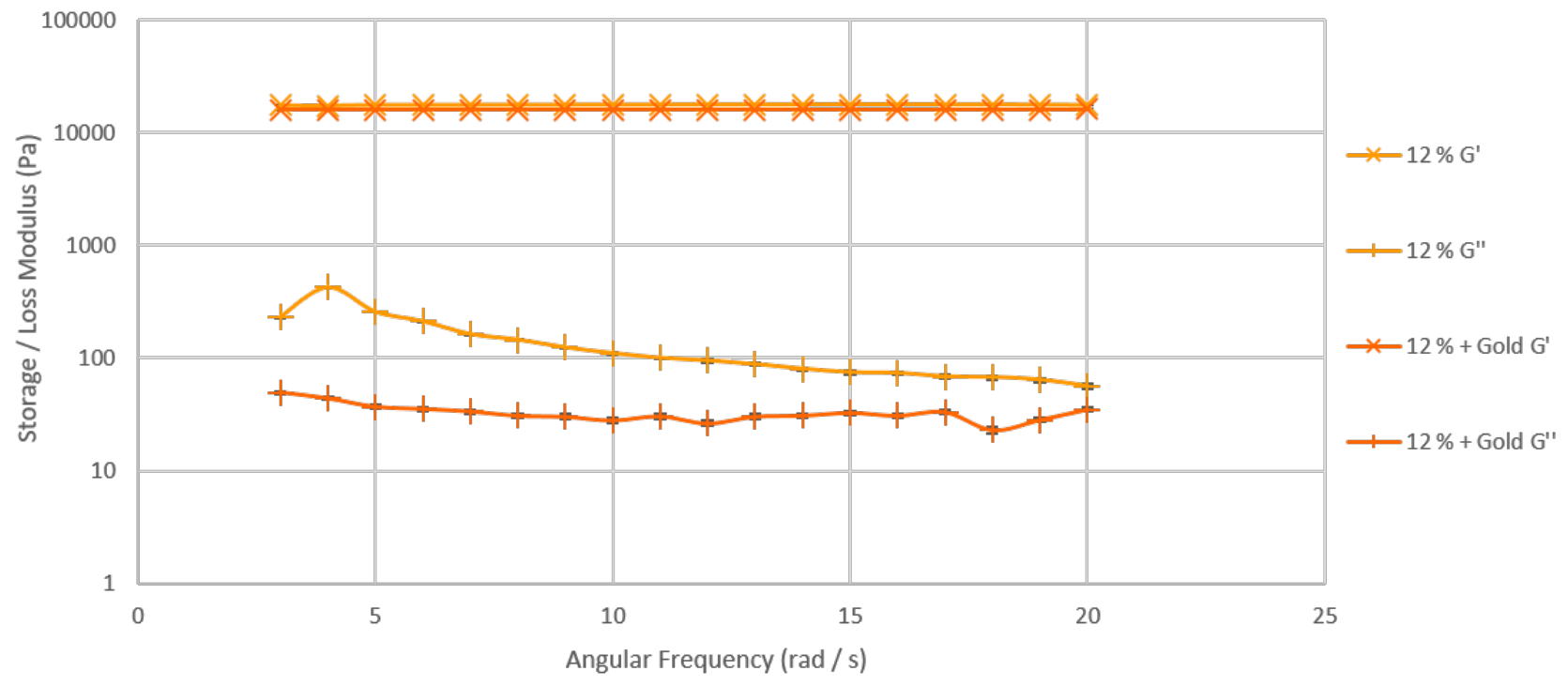

Figure S26. Comparison of average frequency sweep data for $12 \%$ polyacrylamide with and without gold. Error bars represent the Log spread of data. 


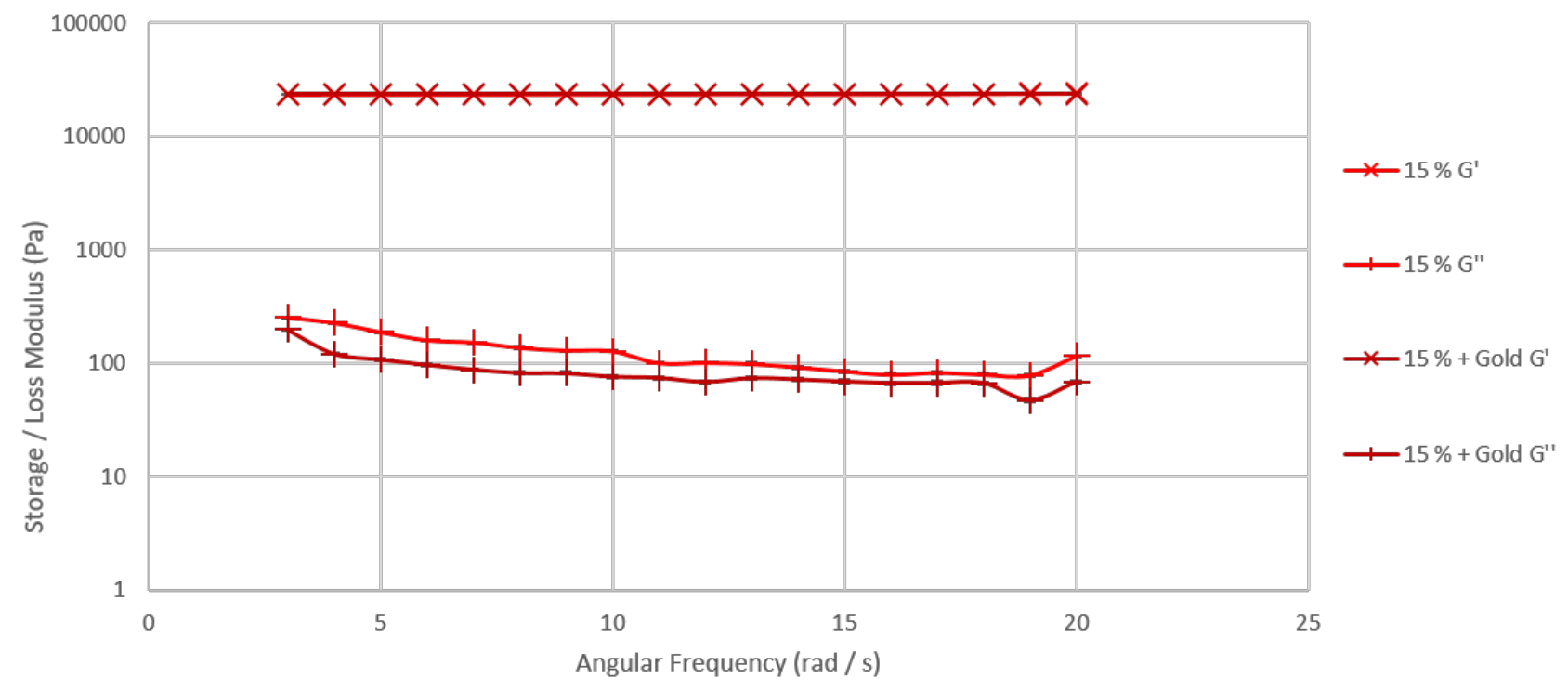

Figure S27. Comparison of average frequency sweep data for $15 \%$ polyacrylamide with and without gold. Error bars represent the Log spread of data.

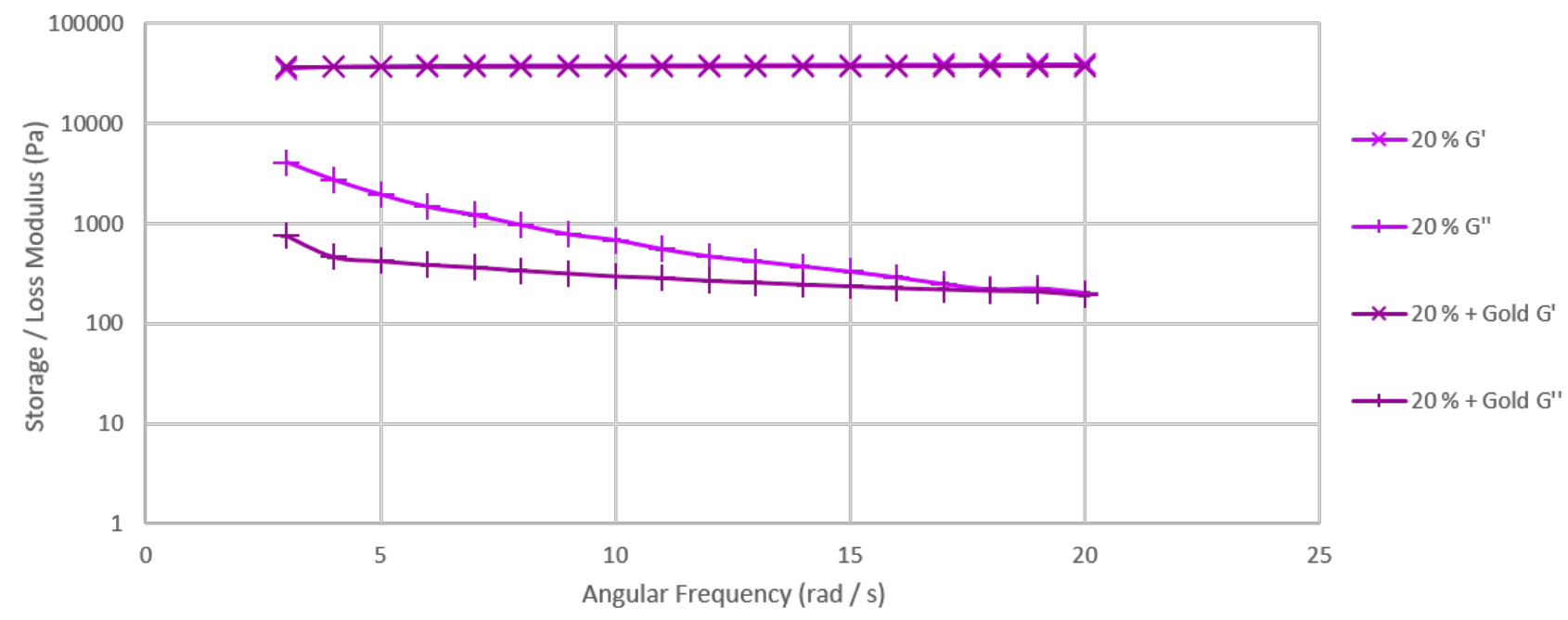

Figure S28. Comparison of average frequency sweep data for $20 \%$ polyacrylamide with and without gold. Error bars represent the Log spread of data. 


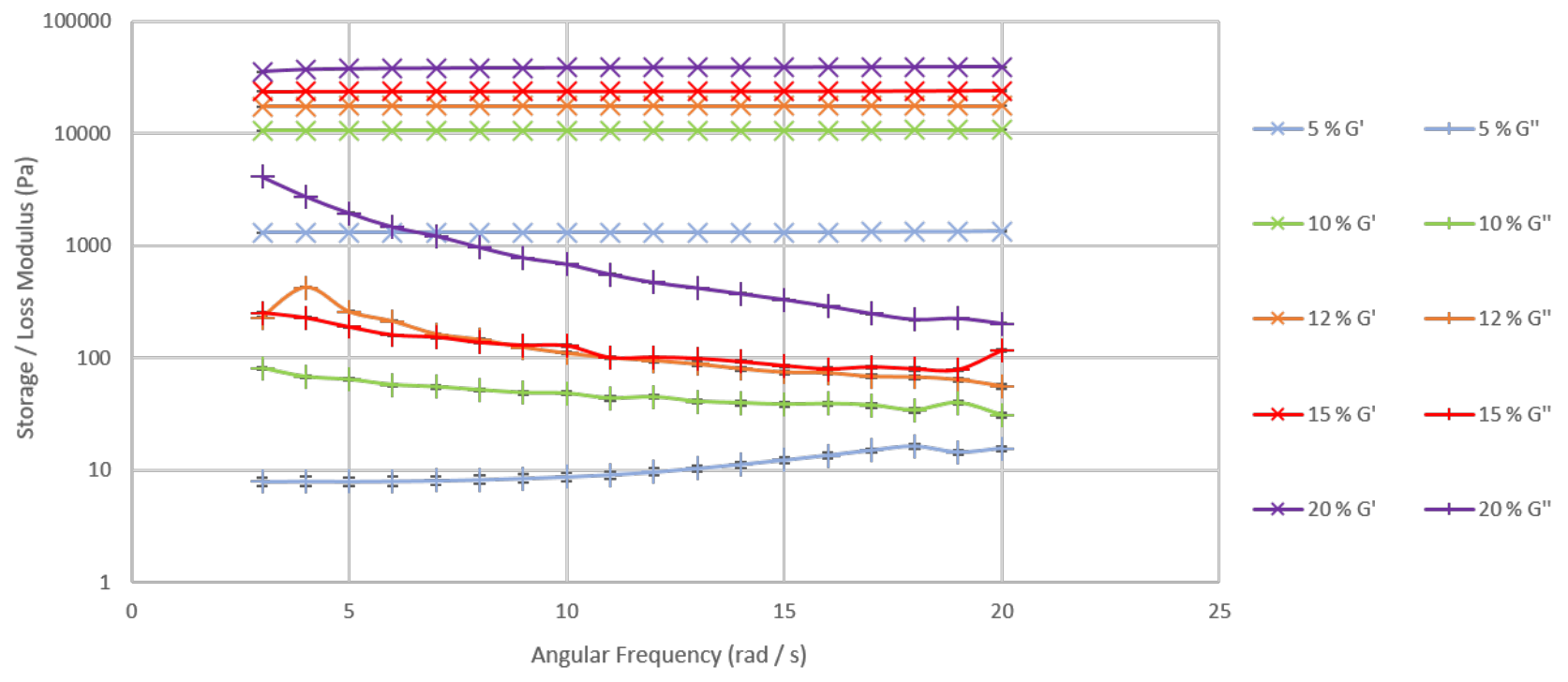

Figure S29. Averaged frequency sweep rheology data for polyacrylamide gel without gold, for percentages; 5, 10, 12, 15 and $20 \%$. Error bars depict the Log spread of data.

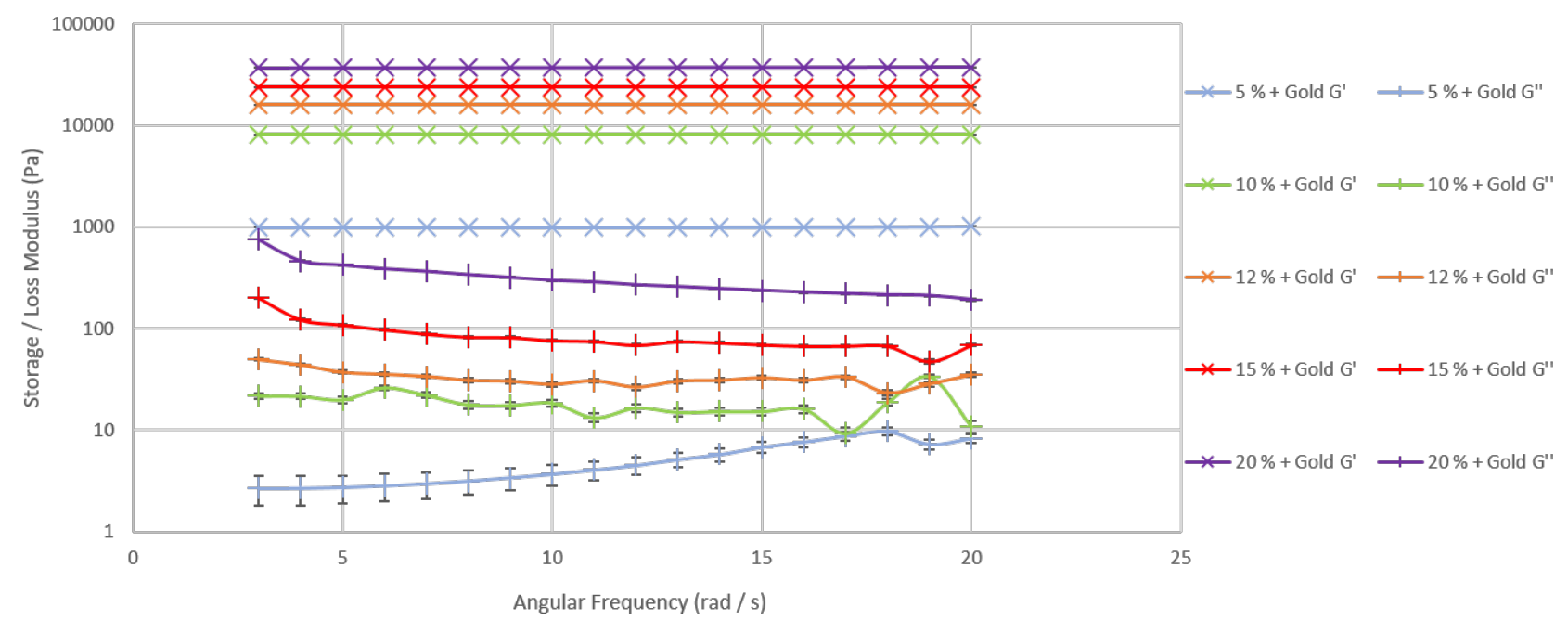

Figure S30. Averaged frequency sweep rheology data for polyacrylamide gel with gold, for percentages; 5 , 10, 12, 15 and $20 \%$. Error bars depict the Log spread of data. 


\section{Optical Coherence Tomography}

Figure S33 shows a representation of the OCT set-up.

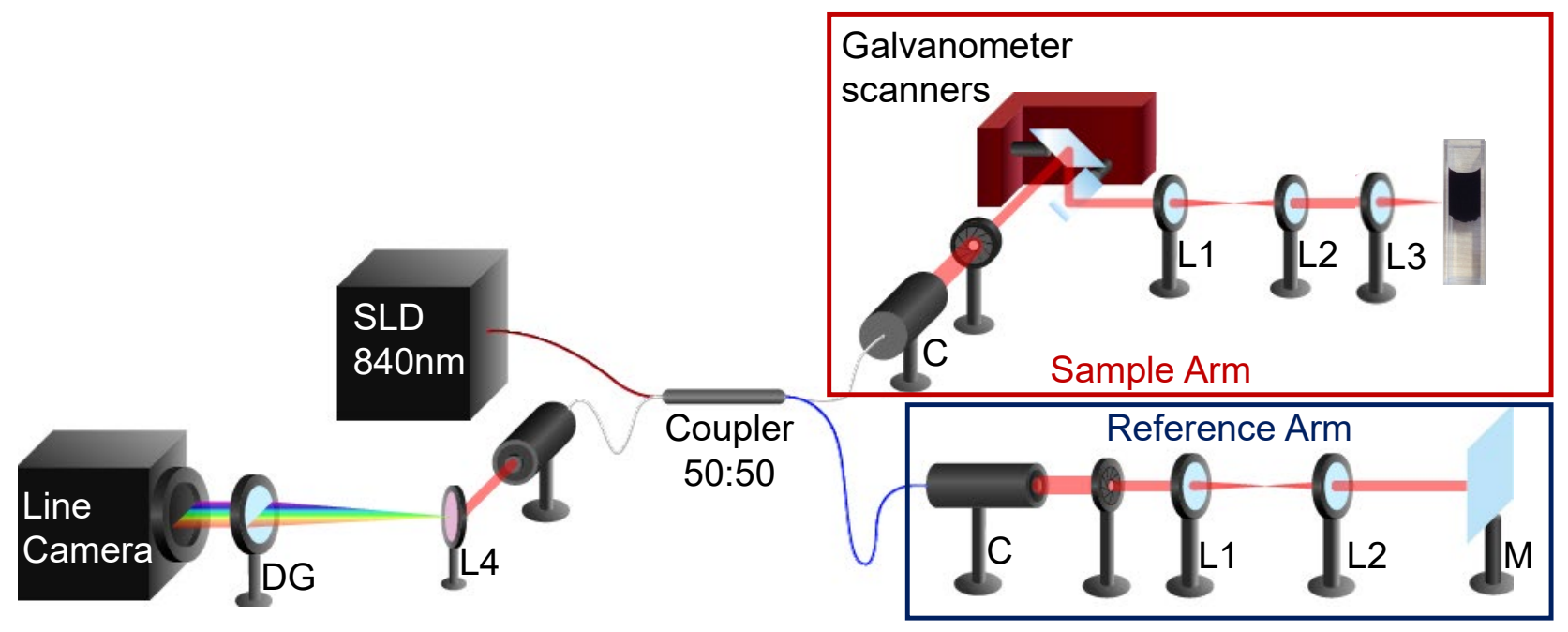

Figure S31. SB-OCT set-up. $L=$ lens; $M=$ mirror; $D G=$ diffraction grating; $C=$ collimator.

The samples were interrogated in a $10 \times 10 \times 30 \mathrm{~mm}$ quartz cuvette (Fig. S34) with an axial range of $2 \mathrm{~mm}$ (measured in air) and with an axial resolution of $14 \mu \mathrm{m}$ (measured in air) and $12 \mu \mathrm{m}$ in the lateral directions. OCT images were obtained of: solutions of dilute and concentrated DMAP protected gold nanoparticles; a $12 \%$ polyacrylamide gel, made with TBE buffer (both with and without DMAP AuNPs), as well as the interface between the two gel layers (+/- AuNPs). OCT images were also obtained for a $10-15 \%$ gradient polyacrylamide gel made with tris- $\mathrm{HCl}$ buffer.

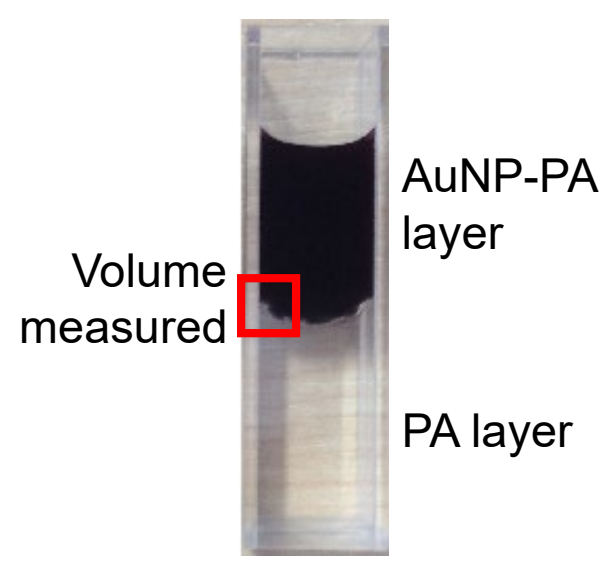

Figure S32. Sample used for OCT measurements.

$1.5 \mathrm{~mL}$ of the non-AuNPs containing gel was deposited into a clean polished cuvette, after being activated by the TEMED and APS. The gel was left to polymerise before $1.5 \mathrm{~mL}$ of the AuNPs containing gel was deposited onto the surface and left to polymerise. Once the gels had fully polymerised the cuvette was attached to a stand and placed in front of the sample beam. The top and bottom layers were imaged separately before the interface was also visualised. A volume (3D image) was then obtained of the interface. This method was repeated for both gel types and a volume was also taken of the TBE AuNPs gel. Images were obtained by the same method as for the as-synthesised DMAP AuNPs and the concentrated DMAP AuNPs. A clean cuvette was filled ( $3 \mathrm{~mL}$ ) with un-concentrated DMAP AuNPs, and the sample was scanned and an image obtained. This was repeated for the concentrated DMAP AuNPs sample (Fig. S35-S36) 


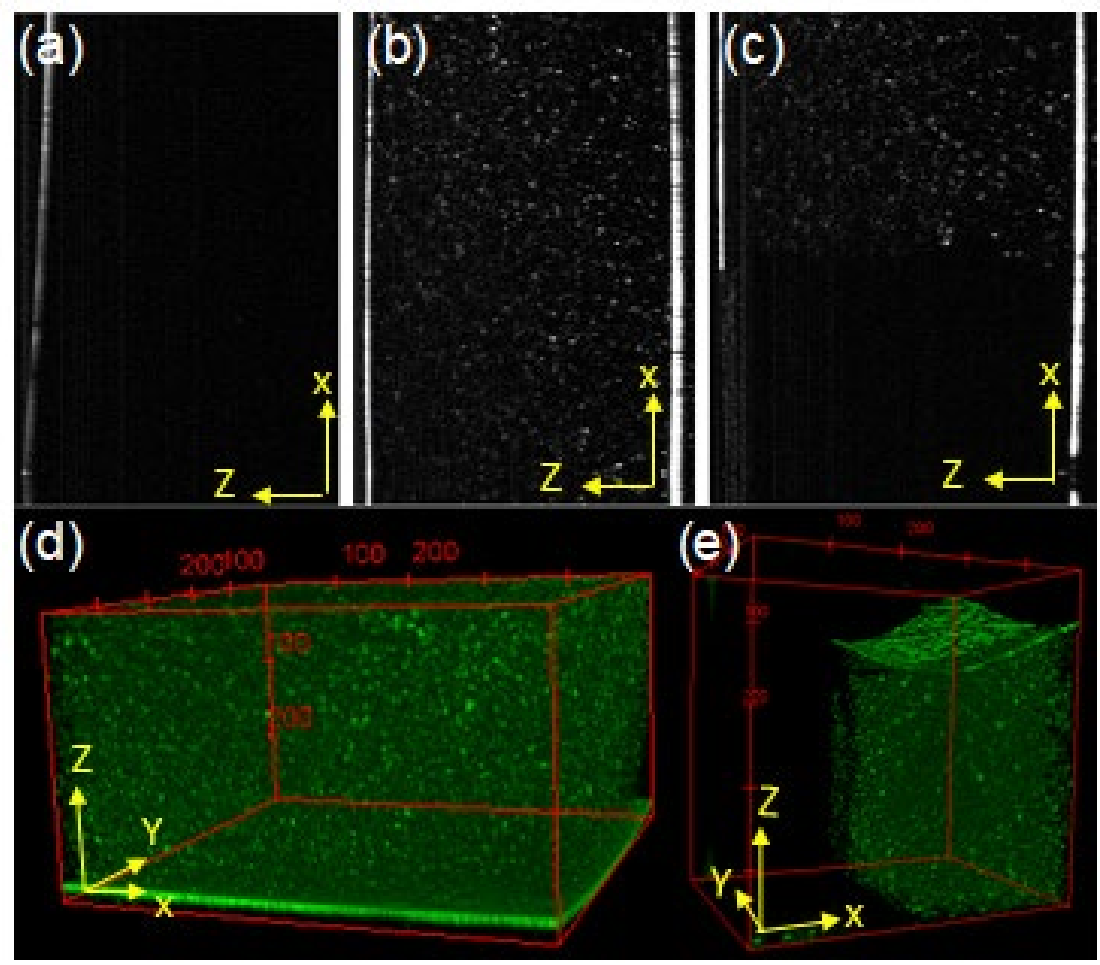

Figure S33. (a), (b) and (c): OCT cross section images (lateral along the vertical direction, $x: 1.5 \mathrm{~mm}$ and along depth direction, z, $1.5 \mathrm{~mm}$ measured in air) showing: (a) TBE native PA gel without AuNPs. (b) TBE native PA gel containing DMAP AuNPs. (c) Interface between the two gels. (d) and (e): OCT volume image (1.5 $\mathrm{mm} x$ $1.5 \mathrm{~mm} \times 1.5 \mathrm{~mm}$ ) showing: (d) AuNP TBE gel; (e) The -AuNP (left) and +AuNP (right) TBE gel interface. The -AuNP gel shows minimal contrast whereas high contrast is seen for the +AuNP section.

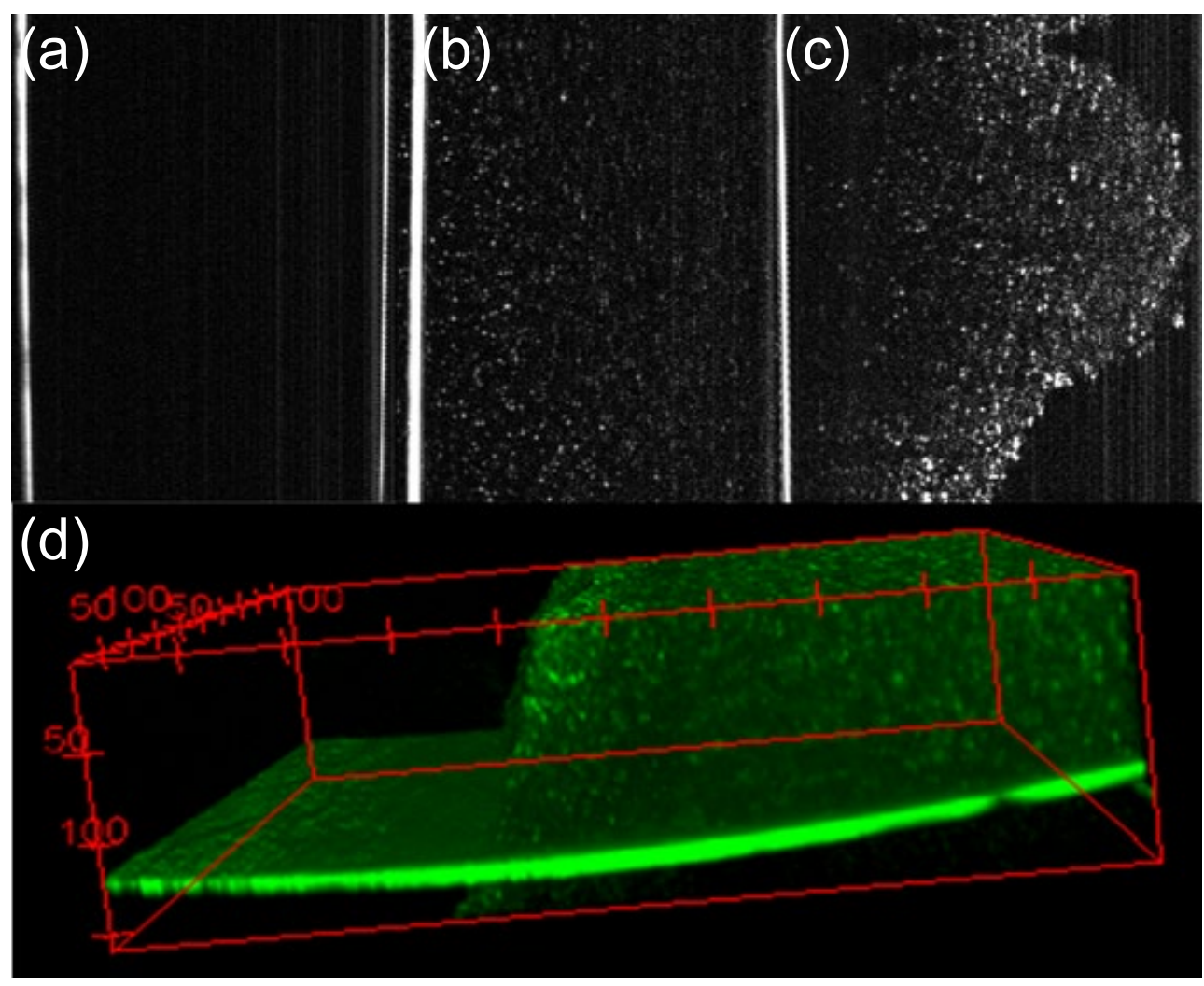

Figure S34. OCT images showing: (a) Tris- $\mathrm{HCl}$ native PA gel without AuNPs. (b) Tris- $\mathrm{HCl}$ native PA gel containing AuNPs. (c) Interface between the two gels. (d) Volume image (1.5 $\mathrm{mm} \times 1.5 \mathrm{~mm} \times 1.5 \mathrm{~mm})$ showing the-AuNP (left) / +AuNP (right) gel interface. 


\section{Transmission Electron Microscopy of Gel Matrices}

For imaging of gel matrices, the gel polymerisation was initiated, and then $2 \mu \mathrm{L}$ drops were placed on carbon coated copper grids for between 10 and 60 seconds, after which the solution was wicked off. After one minute to allow polymerisation to occur, the grids were washed with $2 \mu \mathrm{L}$ of filtered, deionised water, to remove salt deposits from the buffer. The grids were then dried over phosphorous pentoxide for 3 hours before imaging. 


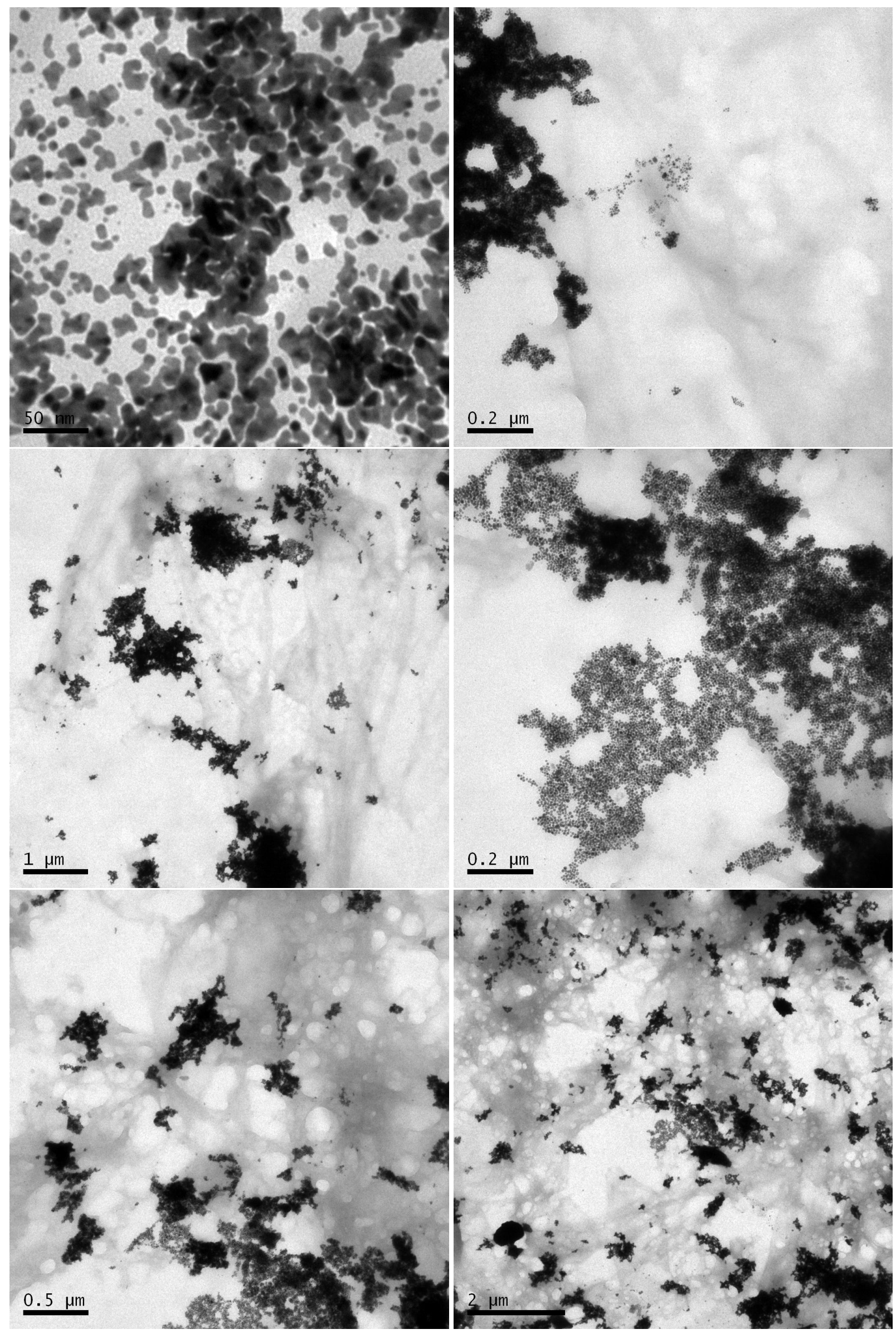

Figure S35. Further TEM images of DMAP AuNPs within the dried polyacrylamide gel matrix. 


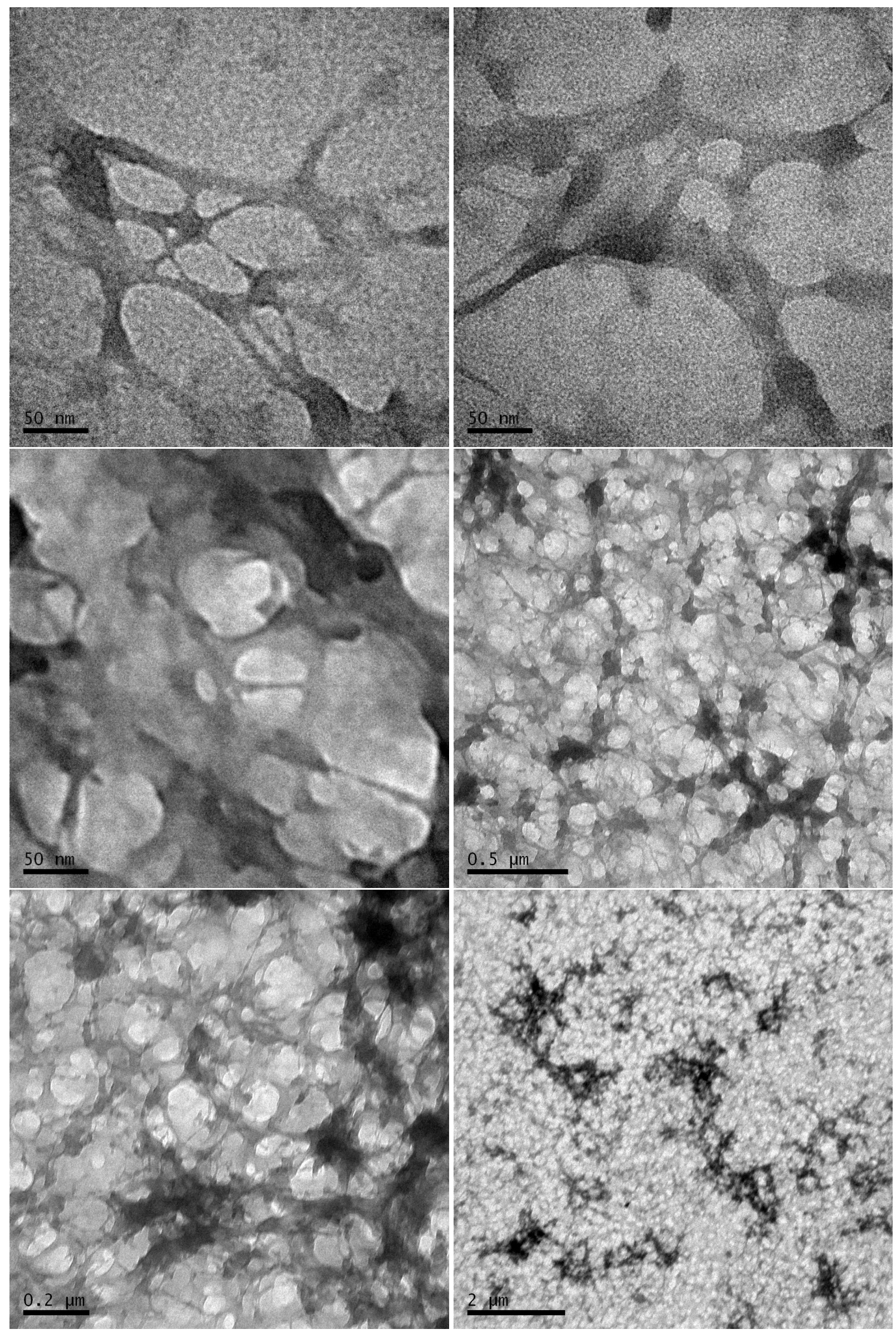

Figure S36. TEM images of the dried polyacrylamide gel matrix. 


\section{References}

1 W. Haiss, N. T. K. Thanh, J. Aveyard and D. G. Fernig, Determination of size and concentration of gold nanoparticles from UV-Vis spectra, Anal. Chem., 2007, 79, 4215-4221.

2 J. Schindelin, I. Arganda-Carreras, E. Frise, V. Kaynig, M. Longair, T. Pietzsch, S. Preibisch, C. Rueden, S. Saalfeld, B. Schmid, J.-Y. Tinevez, D. J. White, V. Hartenstein, K. Eliceiri, P. Tomancak and A. Cardona, Fiji: an open-source platform for biological-image analysis, Nat. Methods, 2012, 9, 676-682.

3 K. L. Lau, G. D. Hamblin and H. F. Sleiman, Gold Nanoparticle 3D-DNA Building Blocks: High Purity Preparation and Use for Modular Access to Nanoparticle Assemblies, Small, 2014, 10, 660-666.

4 M. Brust, M. Walker, D. Bethel, P. J. Schriffen and R. Whyman, Synthesis of Thiol-derivatised Gold Nanoparticles in a Two-phase Liquid-Liquid System, J. Chem. Soc. Chem. Commun., 1994, 801.

5 Y. Abidine, V. M. Laurent, R. Michel, A. Duperray, L. I. Palade and C. Verdier, Physical properties of polyacrylamide gels probed by AFM and rheology, EPL (Europhysics Lett., 2015, 109, 38003. 